\title{
Two-Dimensional Material Molybdenum Disulfides as Electrocatalysts for Hydrogen Evolution
}

\author{
Lei Yang ${ }^{1, *}$, Ping Liu ${ }^{2}$, Jing $\mathrm{Li}^{2}$ and Bin Xiang ${ }^{2, *}$ \\ 1 Key Laboratory of Biomimetic Sensor and Detecting Technology of Anhui Province, School of Materials and \\ Chemical Engineering, West Anhui University, Lu'an 237012, China \\ 2 Department of Materials Science and Engineering, CAS Key Laboratory of Materials for Energy Conversion, \\ Synergetic Innovation Center of Quantum Information and Quantum Physics, University of Science and \\ Technology of China, Hefei 230026, China; 15209835824@163.com (P.L.); 18355187975@163.com (J.L.) \\ * Correspondence: leiyang@wxc.edu.cn (L.Y.); binxiang@ustc.edu.cn (B.X.); \\ Tel.: +86-564-330-5690 (L.Y.); +86-551-6360-7833 (B.X.)
}

Received: 25 August 2017; Accepted: 19 September 2017; Published: 25 September 2017

\begin{abstract}
Recently, transition metal dichalcogenides (TMDs), represented by $\mathrm{MoS}_{2}$, have been proven to be a fascinating new class of electrocatalysts in hydrogen evolution reaction (HER). The rich chemical activities, combined with several strategies to regulate its morphologies and electronic properties, make $\mathrm{MoS}_{2}$ very attractive for understanding the fundamentals of electrocatalysis. In this review, recent developments in using $\mathrm{MoS}_{2}$ as electrocatalysts for the HER with high activity are presented. The effects of edges on HER activities of $\mathrm{MoS}_{2}$ are briefly discussed. Then we demonstrate strategies to further enhance the catalytic performance of $\mathrm{MoS}_{2}$ by improving its conductivity or engineering its structure. Finally, the key challenges to the industrial application of $\mathrm{MoS}_{2}$ in electrocatalytic hydrogen evolution are also pointed out.
\end{abstract}

Keywords: $\mathrm{MoS}_{2}$; active edge sites; electrical conductivity; electronic structure; hydrogen evolution reaction

\section{Introduction}

In recent decades, the development of new energy sources has become a hot topic in academia [1-4]. Hydrogen, with its high energy density $(143 \mathrm{~kJ} / \mathrm{g})$, has been proposed as a promising candidate to replace fossil fuels in the future due to the fact that the only combustion product is water, which is environmentally friendly [5-7]. The hydrogen evolution reaction (HER) has been considered one of the most effective ways to produce clean hydrogen energy [8-11]. Platinum- and noble metal-containing materials have been favored as electrocatalysts due to their high activity and chemical inertness [12-14]. However, the low abundance and high price restrict their large-scale application $[10,15]$. Therefore, exploring new catalysts that are abundant and of low cost has become important.

Recently, two-dimensional (2D) layered transition metal dichalcogenides (TMDs) have been widely reported as promising non-noble metal electrocatalysts due to their abundance, low cost, and highly efficient catalytic activity. Several review papers have summarized the structure, synthesis, and composites of 2D TMDs, as well as their application in HER [16-21]. It is commonly accepted that unique 2D plenary structures provide ultrahigh specific surface area, atomic thickness, and an atomically flat facet [22]. Thus for the 2D TMDs, it is not only easy to achieve high catalytic activity, but also to modify the chemical and physical properties so as to further improve their catalytic performance [23]. Among the many layered TMDs electrocatalysts, $\mathrm{MoS}_{2}$ is the first to emerge as an active HER catalyst [24], and it continues to be explored as a prototypical model. Theoretical calculations and experimental results have revealed that the basal plane of $\mathrm{MoS}_{2}$ is semiconducting and catalytically inert, whereas the surface edges are metallic and chemically active [24-26]. It has been 
proposed that the key factor determining the hydrogen evolution efficiency of a catalyst is the Gibbs free energy for hydrogen adsorption on the active site $\left(\Delta G_{H}\right)[24,27,28]$. If the chemical bonds between the catalyst and the hydrogen are too strong, it would lead to permanent blocking of the catalytic surface. If the temporary chemical bonds are too weak, it would cause the adsorbate residence time to be too short for bond breaking [29,30]. Therefore, an optimal catalyst should have the Gibbs free energy for hydrogen adsorption close to zero $\left(\Delta G_{H} \approx 0\right)$ [29-32]. Figure 1a shows the "volcano plot" of exchange current density as a function of hydrogen adsorption Gibbs free energy for various HER catalyst materials [25]. The Pt and some other noble metal materials are at the top of the HER "volcano" and the hydrogen absorption energy of Pt is just slightly less than zero. The calculated Gibbs free energy for $\mathrm{MoS}_{2}$ edges is just $+0.08 \mathrm{~V}$ when the $\mathrm{H}$ coverage is $25 \%$, very close to the optimum value of $0 \mathrm{eV}$ [24]. Therefore, $\mathrm{MoS}_{2}$ is a potential alternative to expensive noble metals.
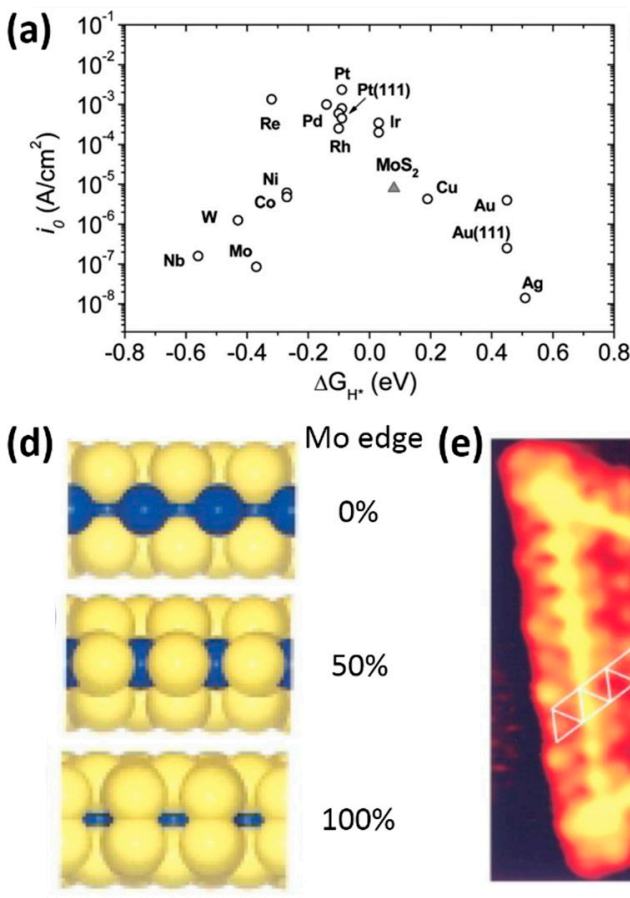
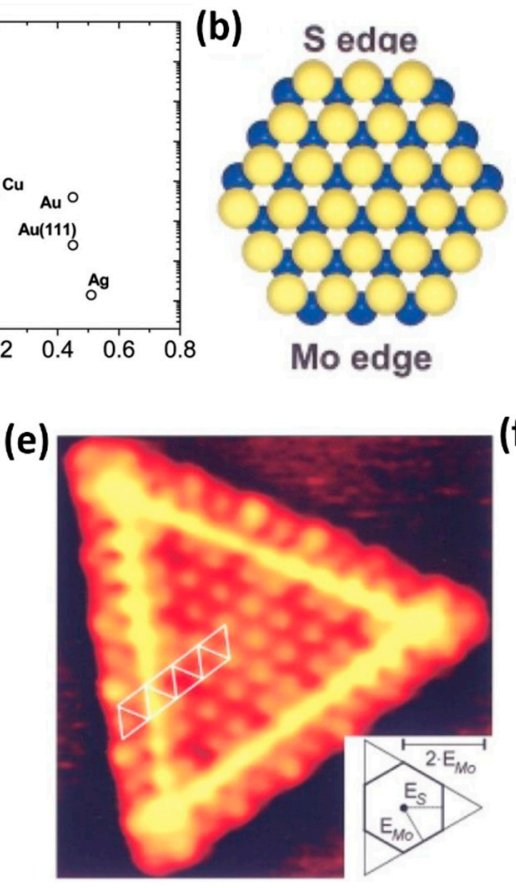

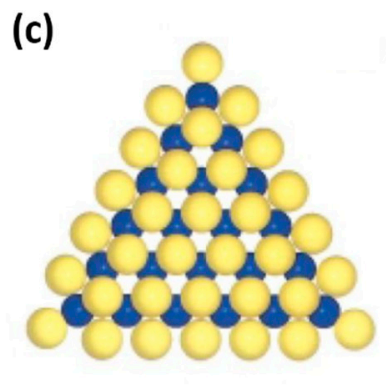

(f)

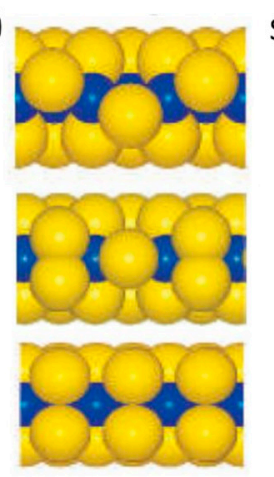

S edge

$50 \%$

$75 \%$

$100 \%$

Figure 1. (a) "Volcano plot" of experimentally measured exchange current density as a function of the DFT-calculated Gibbs free energy of adsorbed atomic hydrogen for vary catalysts [25]; (b) Molecular model of a bulk truncated $\mathrm{MoS}_{2}$ hexagon with Mo and S edges being exposed [33]; (c) Triangular shape of $\mathrm{MoS}_{2}$ exposing Mo edges (Mo atoms terminate with S dimers) [33]; (d) Side view of Mo edges with $0 \%, 50 \%$ and $100 \%$ coverage, respectively [33]; (e) An atom-resolved STM images of $\mathrm{MoS}_{2}$ clusters [33]; (f) (1010) S edge with varying sulfur coverage [34]. Reproduced from [25] with permission from copyright 2007 American Association for the Advancement of Science, [33] with permission from copyright 2000 The American Physical Society, and [34] with permission from copyright 2007 Nature Publishing Group.

Recently, great efforts have been dedicated to enhancing the electrocatalytic activities of TMDs in HER. Generally, there are three directions: the first is improving the catalytic activities of the edge sites; the second is exposing or increasing the number of active edge sites; the third is optimizing the electronic structure or improving the electrical conductivity of the catalyst [35-38]. This review attempts to summarize the recent progress in nanostructured $\mathrm{MoS}_{2}$ as representative TMD electrocatalysts toward the HER. Firstly, the role of the edges of $\mathrm{MoS}_{2}$ in a HER will be introduced. Then we will summarize the concrete approaches to further enhancing the catalytic performance of $\mathrm{MoS}_{2}$, like activating the inert $\mathrm{S}$ edges via doping, forming an amorphous structure, growing 
$\mathrm{MoS}_{2}$ on conductive carbon-based substrates, exerting strain, etc. In the end, we will briefly discuss the challenges pertaining to the rapid development of $\mathrm{MoS}_{2}$ as well as its industrial applications.

\section{Edge Structures of $\mathrm{MoS}_{2}$}

Bulk $\mathrm{MoS}_{2}$ is a layered material composed of a two-dimensional S-Mo-S "sandwich-like" structure [31,39]. For each individual layer, $\mathrm{MoS}_{2}$ prefers to expose two types of low index edge terminations: the (11010) S edge and the (1010) Mo edge, as shown in Figure 1b [33,40,41]. When the size becomes smaller, like the $\mathrm{MoS}_{2}$ cluster synthesized on $\mathrm{Au}$ (111), a triangular shape feature can be observed (Figure 1c) [33]. The triangular sharp domain only exposes one of the two types of low index edges $[33,34]$. According to the simple Wulff-type construction argument, the energetically favored one has priority to survive, so that the (1010) Mo edge terminates the $\mathrm{MoS}_{2}$ triangle domains [33,34]. Inside $\mathrm{MoS}_{2}$ "sandwich" layers, the Mo atoms symmetrically bond with six $\mathrm{S}$ atoms, which means that the Mo atoms are saturated with S atoms [33,34]. Density functional theory (DFT) calculations have shown that the Mo edges become unstable when there are dangling Mo bonds on the edge [33,34]. As the edges have no perfect trigonal prismatic coordination, the energetic favorable form of the edge can be the structure with one S (50\% coverage) or two S atoms (100\% coverage) per Mo edge atom (called S dimers), as shown in Figure 1d [33,34]. In both cases, similar to the situation with Mo atoms inside of $\mathrm{MoS}_{2}$, the Mo atoms are saturated by bonding with six $\mathrm{S}$ atoms. These results are consistent with the scanning tunneling microscope (STM) characterizations of $\mathrm{MoS}_{2}$ clusters, which show that the $S$ atoms at the edge are shifted by half a lattice constant relative to the $S$ atoms in the basal plane (Figure 1e) [33].

When the size of the $\mathrm{MoS}_{2}$ triangles cluster becomes even smaller (when the number of Mo atoms on the side of a triangle is less than 21), the edge only exposes the (1010) S edge with varying S coverage (Figure 1f) [34]. The 50\% and $75 \% \mathrm{~S}$ coverage of the $\mathrm{S}$ edges is slightly less stable than that of the $100 \%$ saturated $\mathrm{S}$ edge [34].

As a HER catalyst, the active edges of nanostructured $\mathrm{MoS}_{2}$ are mainly from the Mo edges, whereas the $S$ edges are inert $[36,42,43]$. The $S$ edges constitute almost half of the exposed edge sites of the $\mathrm{MoS}_{2}$ catalyst [43]. Therefore, activating the inert edge sites is an efficient way to enhance its electrocatalytic activity.

\section{Strategies for Improving the HER Activity of $\mathrm{MoS}_{2}$}

\subsection{Activating the Inert S Edges via Doping}

To enhance the catalytic performance of $\mathrm{MoS}_{2}$ via activating the inert $\mathrm{S}$ edges, Bonde et al. have synthesized cobalt-doped $\mathrm{MoS}_{2}$ nanoparticles on Toray carbon paper using $\left(\mathrm{NH}_{4}\right)_{6} \mathrm{Mo}_{7} \mathrm{O}_{24} \cdot 4 \mathrm{H}_{2} \mathrm{O}$ and $\mathrm{C}_{4} \mathrm{H}_{4} \mathrm{CoO}_{4} \cdot 4 \mathrm{H}_{2} \mathrm{O}$ as reactants [36]. Electrochemical characterizations showed that the cobalt exerted a promoted effect on $\mathrm{MoS}_{2}$ catalytic activities. The introduction of Co into $\mathrm{MoS}_{2}$ edges decreased the Tafel slope from $120 \mathrm{mV} /$ dec to $101 \mathrm{mV} /$ dec (Figure 2a). DFT calculations showed that the incorporation of cobalt into the $\mathrm{MoS}_{2}$ edges reduced the hydrogen adsorption $\Delta \mathrm{G}_{\mathrm{H}}$ of $\mathrm{S}$ edge from $0.18 \mathrm{eV}$ to $0.1 \mathrm{eV}$ (Figure $2 \mathrm{~b}$ ), while the $\Delta G_{H}$ of Mo edge $(0.08 \mathrm{eV})$ was not affected due to its more stable structure.

In the form of Co-doped $\mathrm{MoS}_{2}$, the Co dopants might be distributed on the entire lattice structure of the $\mathrm{MoS}_{2}$ instead of being limited on the edges, which might also promote the terrace site activities [43]. The incorporation of Co metal atoms can change the morphology of $\mathrm{MoS}_{2}$. As a result, it is hard to distinguish whether the activity promotion effect was from doping or from the effect of an increased surface area caused by the morphology change of $\mathrm{MoS}_{2}$. To minimize this doubt, Wang et al. have synthesized a transition metal ( $\mathrm{Fe}, \mathrm{Co}, \mathrm{Ni}$, and $\mathrm{Cu}$ )-doped $\mathrm{MoS}_{2}$ nanofilm with fixed morphology via a chemical vapor deposition (CVD) method [43]. The doped $\mathrm{MoS}_{2}$ nanofilm was composed of vertically aligned molecular layers. The surface of the nanofilm was totally covered by the edge sites, confirming that the enhanced catalytic performance came from 
the transition-metal-doped edge sites. Figure $2 \mathrm{c}$ shows the polarization curves of the pristine and transition-metal-doped $\mathrm{MoS}_{2}$ nanofilm, respectively. For the $\mathrm{Fe}-, \mathrm{Co}-, \mathrm{Ni}-$, and $\mathrm{Cu}$-doped $\mathrm{MoS}_{2}$, the current densities at the overpotential of $-300 \mathrm{mV}$ were $2.3,3.5,2.4$, and $2.6 \mathrm{~mA} / \mathrm{cm}^{2}$, respectively, which were three times higher than that of pristine one. The Tafel slope (Figure $2 \mathrm{~d}$ ) was in the range of 117 to $103 \mathrm{mV} /$ dec for those doped $\mathrm{MoS}_{2}$, lower than the $118 \mathrm{mV} / \mathrm{dec}$ in a pure $\mathrm{MoS}_{2}$ nanofilm. At the same time, the exchange current densities of the doped $\mathrm{MoS}_{2}$ were also larger than those of the pristine $\mathrm{MoS}_{2}$. To illustrate the enhanced behavior, they also performed DFT calculations. The calculated results suggested that the doped $S$ edges had an energy value closer to thermo-neutral $\Delta \mathrm{G}_{\mathrm{H}}$ and became similarly active to the pristine Mo edge, consistent with the results reported by Bonde's group. Therefore, activating the inert $\mathrm{S}$ edges via a doping method is an efficient way to enhance the HER performance of $\mathrm{MoS}_{2}$.

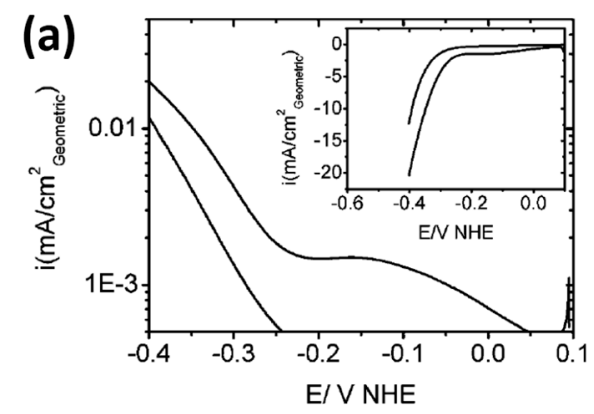

(c)

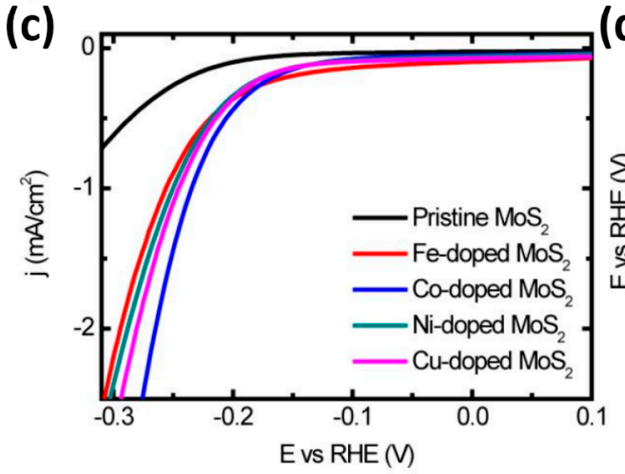

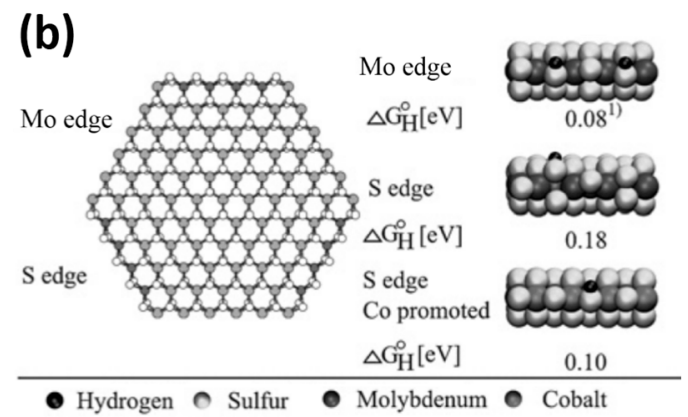

(d)

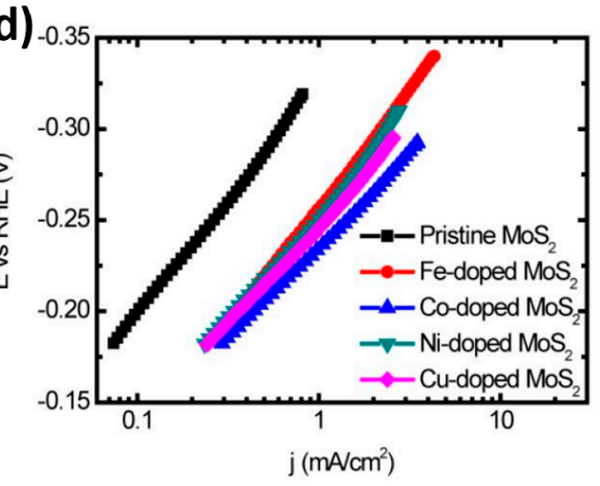

Figure 2. (a) Tafel plots and polarization curves (inset) of the HER on $\mathrm{MoS}_{2}$ and cobalt-doped $\mathrm{MoS}_{2}$ [36]; (b) Left: molecular model of a hexagon $\mathrm{MoS}_{2}$ exposing both the $\mathrm{S}$ edge and the Mo edge. Right: differential free energies of hydrogen adsorption [36]; (c) Polarization curves and (d) Tafel plots of the pristine and transition metal doped $\mathrm{MoS}_{2}$ nanofilms [43]. Reproduced from [36] with permission from copyright 2008 The Royal Society of Chemistry and [43] with permission from Springer.

\subsection{Increasing the Number of Active Sites}

\subsubsection{Forming an Amorphous Structure}

Previous studies have shown that the high HER activity of the edges is derived from unsaturated atoms at the edges $[24,25,35]$. Amorphous $\mathrm{MoS}_{2}$ has many coordinately unsaturated atoms that may serve as active sites and eventually lead to the evolution of hydrogen [44]. Shin and co-workers have successfully prepared an amorphous $\mathrm{MoS}_{2}$ catalyst on Au by the atomic layer deposition method (Figure 3a,b) [45]. Electrochemical characterizations showed that the amorphous $\mathrm{MoS}_{2}$ thin film exhibited excellent HER activity. Compared with the reported amorphous $\mathrm{MoS}_{x}$, the $\mathrm{MoS}_{2}$ thin film exhibited a much higher turnover frequency (TOF) of $3 \mathrm{H}_{2} / \mathrm{s}$ at $0.215 \mathrm{~V}$ Vs Reversible Hydrogen Electrode (RHE). The Tafel slope was $47 \mathrm{mV} / \mathrm{dec}$, close to the value in Pt. The amorphous $\mathrm{MoS}_{2}$ 
thin film also exhibited high electrical conductivity $\left(0.22 \Omega^{-1} \mathrm{~cm}^{-1}\right.$ at room temperature) and low activation energy $(0.027 \mathrm{eV})$.
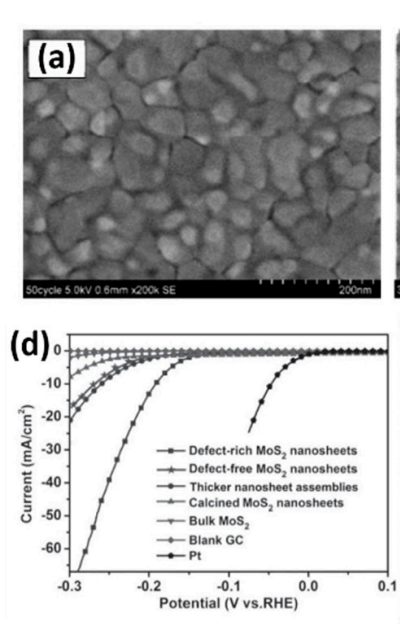
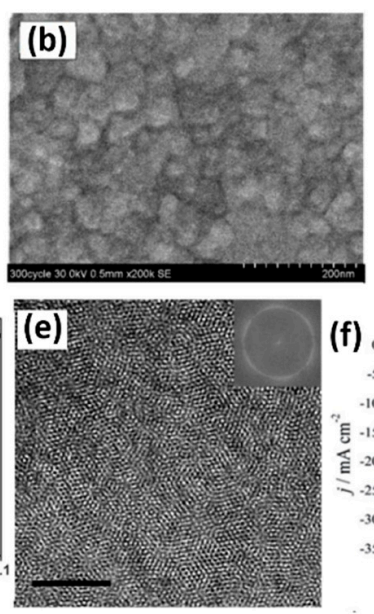
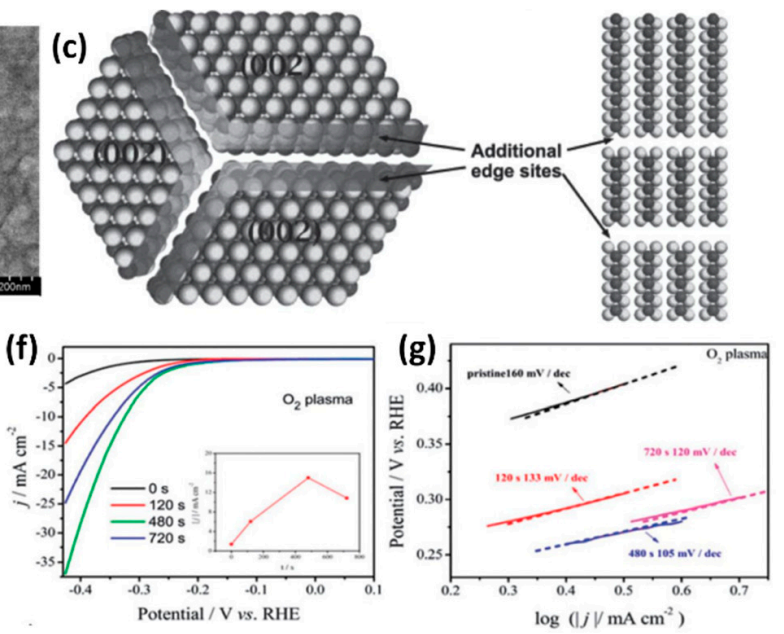

Figure 3. (a,b) SEM images of amorphous $\mathrm{MoS}_{2}$ thin film on $\mathrm{Au}$ [45]; (c) Schematic illustrations of additional active edge sites were designated by gray shading [46]; (d) Polarization curves of various samples as indicated [46]; (e) HRTEM image and corresponding FFT patterns of $\mathrm{MoS}_{2}$ with certain degree of disorder synthesized at $140{ }^{\circ} \mathrm{C}$. The scale bar represents $5 \mathrm{~nm}$ [47]; (f) The polarization curves and (g) Tafel plots of $\mathrm{O}_{2}$ plasma-treated $\mathrm{MoS}_{2}$ [48]. Reproduced from [45,47] with permission from copyright American Chemical Society [46] with permission from copyright 2013 Wiley, and [48] with permission from copyright 2015 The Royal Society of Chemistry.

\subsubsection{Creating Defective $\mathrm{MoS}_{2}$ Nanosheets}

Another efficient way to increase the number of active sites of $\mathrm{MoS}_{2}$ is defect engineering. Xie et al. have put forward a way to engineer a defect of $\mathrm{MoS}_{2}$ by forming cracks on the surface of $\mathrm{MoS}_{2}$ [46]. They achieved this by designing a reaction between the precursors and different amounts of thiourea. This indicated that the excess thiourea was necessary for the formation of the crack structure because the excess thiourea can be adsorbed on primary nanocrystallites, which partially hinder the oriented crystal growth. The defect-rich $\mathrm{MoS}_{2}$ ultrathin nanosheets with rich active sites exhibited excellent HER activity. The onset overpotential of the defect-rich $\mathrm{MoS}_{2}$ was $-120 \mathrm{mV}$, much smaller than that of the defect-free one (Figure 3d). Compared with the defect-free $\mathrm{MoS}_{2}$, the defect-rich $\mathrm{MoS}_{2}$ also exhibited a smaller Tafel slope and larger cathodic current density. Besides the cracks, the disorder feature in $\mathrm{MoS}_{2}$ is also beneficial for its catalytic performance. By controlling the temperature during synthesis, Xie et al. have also realized the controllable disorder in the oxygen-incorporated $\mathrm{MoS}_{2}$ ultrathin nanosheets [47]. By reducing the reaction temperature from $200{ }^{\circ} \mathrm{C}$ to $140{ }^{\circ} \mathrm{C}$ in the Teflon-lined autoclave, atom construction on the basal surface was modified from regular to disorder. The high-resolution transmission electron microscope (HRTEM) image of $\mathrm{MoS}_{2}$ with certain disorder features is shown in Figure 3e. The disorder structure can offer a large number of unsaturated sulfur atoms, which are the active sites for HER. To investigate the HER activity, electrochemical measurements of the oxygen-incorporated $\mathrm{MoS}_{2}$ ultrathin nanosheets with different degrees of disorder have been undertaken. The electrochemical results suggested that the disorder feature had a promoting effect on the HER. When the degree of disorder increases, more unsaturated sulfur atoms can be exposed as active sites for HER, thus further enhancing its catalytic performance.

Plasma treatment is another efficient way to generate defects in $\mathrm{MoS}_{2}$ [48,49]. Wang's group reported a simple plasma $\left(\mathrm{O}_{2}\right.$ and Ar plasma) engineering method to modify the surface properties of $\mathrm{MoS}_{2}$ thin films [48]. For the $\mathrm{O}_{2}$ plasma treated $\mathrm{MoS}_{2}$, the current density at $-350 \mathrm{mV}$ under different treatment time of $120 \mathrm{~s}, 480 \mathrm{~s}$, and $720 \mathrm{~s}$ was $6.11 \mathrm{~mA} / \mathrm{cm}^{2}, 15.17 \mathrm{~mA} / \mathrm{cm}^{2}$, and $10.97 \mathrm{~mA} / \mathrm{cm}^{2}$, 
respectively, much higher than that of pristine $\mathrm{MoS}_{2}$ thin films $\left(1.39 \mathrm{~mA} \mathrm{~cm}{ }^{-2}\right)$. The Tafel slope for the $120 \mathrm{~s}, 480 \mathrm{~s}$, and $720 \mathrm{~s}$ treatment time was $133 \mathrm{mV} / \mathrm{dec}, 105 \mathrm{mV} / \mathrm{dec}$, and $120 \mathrm{mV} /$ dec, respectively. The HER performance could be promoted by increasing the plasma irradiation time from $120 \mathrm{~s}$ to $480 \mathrm{~s}$ because it induced more defects (Figure 3f,g). However, as the treatment time was increased to $720 \mathrm{~s}$, the current density decreased. It could be due to the removal of the $\mathrm{MoS}_{2}$ film under the long-term plasma etching. The HER performance results from Ar plasma-treated $\mathrm{MoS}_{2}$ were similar to that of $\mathrm{O}_{2}$ plasma treated $\mathrm{MoS}_{2}$. After the treatment of $\mathrm{O}_{2}$ or Ar plasma on $\mathrm{MoS}_{2}$, the generated defects enhanced the $\mathrm{MoS}_{2}$ electrocatalytic activity for HER.

\subsubsection{Nanostructuring $\mathrm{MoS}_{2}$ with Various Morphologies}

Increasing the number of active sites by maximally exposing the edges is another efficient way to enhance HER performance. Cui's group successfully synthesized $\mathrm{MoS}_{2}$ thin films with vertically aligned layers, so that the edges can be maximally exposed on the surface [50]. During the synthesis, they deposited the Mo thin films on the substrate, then developed a rapid sulfurization process to convert Mo films into $\mathrm{MoS}_{2}$ films (Figure 4a). Benefiting from the edges on the surface, these edge-terminated films (Figure $4 \mathrm{~b}$ ) were expected to maximize the catalytic activity for a HER. The TOF of those vertically aligned $\mathrm{MoS}_{2}$ films at $0 \mathrm{~V}$ was $0.013 \mathrm{~s}^{-1}$. The exchange current density of the $\mathrm{MoS}_{2}$ films was $2.2 \times 10^{-6} \mathrm{~A} / \mathrm{cm}^{2}, 10$ times higher than that reported for the $\mathrm{MoS}_{2}$ nanoparticle. However, the Tafel slope was in the range of $105-120 \mathrm{mV} / \mathrm{dec}$. Kibsgaard and co-workers have also synthesized $\mathrm{MoS}_{2}$ films to preferentially expose the edge sites [51]. The $\mathrm{MoS}_{2}$ films exhibited double-gyroid bicontinuous network morphology with nanoscale pores. The schematic illustration for the synthesis procedure is shown in Figure 4c. The high surface curvature combined with the nanoscale pores made the $\mathrm{MoS}_{2}$ films expose a high density of edge sites, leading to excellent electrocatalytic activity for HER (a low onset overpotential of $-150 \mathrm{mV}$ and a Tafel slope of $50 \mathrm{mV} / \mathrm{dec}$ ).

(a)

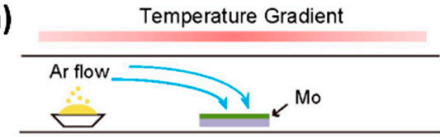

(b)

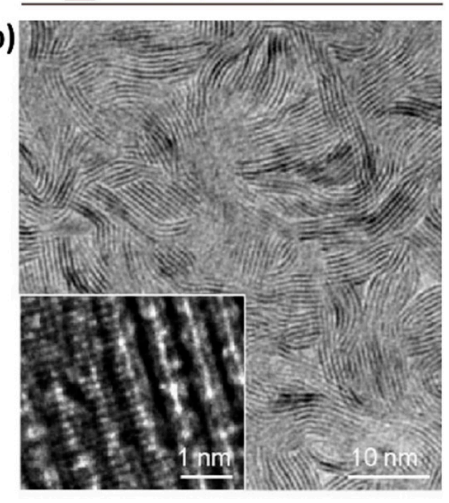

(c)

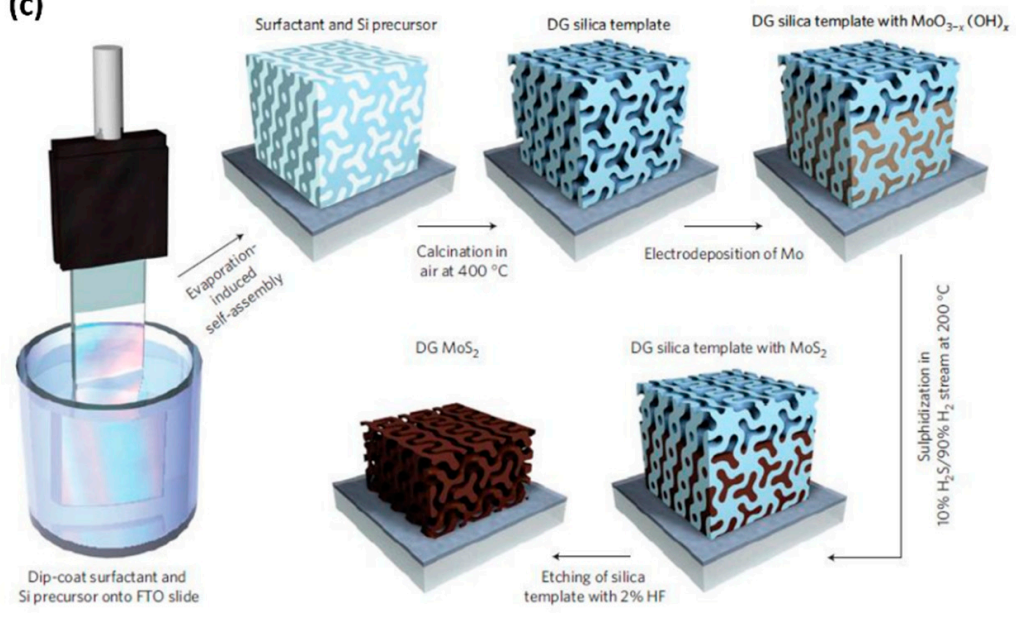

Figure 4. (a) Schematic illustration of the synthesis process of vertically aligned $\mathrm{MoS}_{2}$ film [50]; (b) TEM image of vertically aligned $\mathrm{MoS}_{2}$ that clearly shows the exposed edges. The inset figure was the HRTEM image, which revealed individual layers consisting of three atomic planes in the sequence of S-Mo-S [50]; (c) Synthesis procedure and structural model for mesoporous $\mathrm{MoS}_{2}$ with a double-gyroid morphology [51]. Reproduced from [50] with permission from copyright 2013 American Chemical Society and [51] with permission from copyright 2012 Nature Publishing Group.

\subsubsection{Lowering the Dimension of $\mathrm{MoS}_{2}$}

Lowering the dimension of $\mathrm{MoS}_{2}$ is also an efficient way to increase the number of active sites. Shi et al. have reported the scalable synthesis of monolayer $\mathrm{MoS}_{2}$ on Au foils by a CVD method [52]. Upon varying the growth temperature or the precursor substrate distance, a monolayer triangular 
shape $\mathrm{MoS}_{2}$ with different coverage was obtained. For the monolayer $\mathrm{MoS}_{2}$ with a coverage of $10 \%$, the cathodic current density at $\eta=-300 \mathrm{mV}$ was $3.9 \mathrm{~mA} / \mathrm{cm}^{2}$, and the Tafel slope was $74 \mathrm{mV} / \mathrm{dec}$. It is indicated that the HER performance was much better than that of bulk $\mathrm{MoS}_{2}$ (Figure 5a-c). In addition, when the coverage was increased to $80 \%$, the current density at $\eta=-300 \mathrm{mV}$ reached $50.5 \mathrm{~mA} / \mathrm{cm}^{2}$, and the Tafel slope decreased to $61 \mathrm{mV} / \mathrm{dec}$. Therefore, the increased coverage with the increased edge density can enhance the electrocatalytic performance of $\mathrm{MoS}_{2}$. Recently, we have successfully synthesized one-dimensional $\mathrm{MoS}_{2}$ nanobelts (Figure 5d) based on a CVD method with modified growth conditions [53]. High-resolution scanning transmission electron microscope (HRSTEM) characterization indicated that the (001) basal planes of the $\mathrm{MoS}_{2}$ nanobelt were vertically standing on the substrate (Figure 5e,f) and the edges of the base planes formed the top surfaces of the nanobelt. The onset overpotential of the nanobelts was $-170 \mathrm{mV}$, much lower than that of monolayer $\mathrm{MoS}_{2}$. A smaller Tafel slope was observed in the nanobelts $(70 \mathrm{mV} / \mathrm{dec})$ compared with monolayer $\mathrm{MoS}_{2}$ ( $90 \mathrm{mV} / \mathrm{dec}$ ). The edges on the top surface provide a high density of edge sites, so that the nanobelts can exhibit superior catalytic activity to the monolayer $\mathrm{MoS}_{2}$ (Figure 5g,h). Further decreasing the size of $\mathrm{MoS}_{2}$ by forming quasi-zero-dimensional nanoparticles could further improve the HER performance. Li's group prepared mono-dispersed molybdenum sulfide nanoparticles (Figure $5 \mathrm{i}$ ) from bulk $\mathrm{MoS}_{2}$ by a combination of ultrasonication and centrifugation [54]. X-ray photoelectron spectroscopic characterizations revealed that the as-synthesized sample was $\mathrm{MoS}_{2}$ nanoparticles with abundant $\mathrm{S}$ edges. These active edges made $\mathrm{MoS}_{2}$ exhibit outstanding HER electrocatalytic activity: an onset potential of $-90 \mathrm{mV}$ and a Tafel slope of $69 \mathrm{mV} / \mathrm{dec}$.
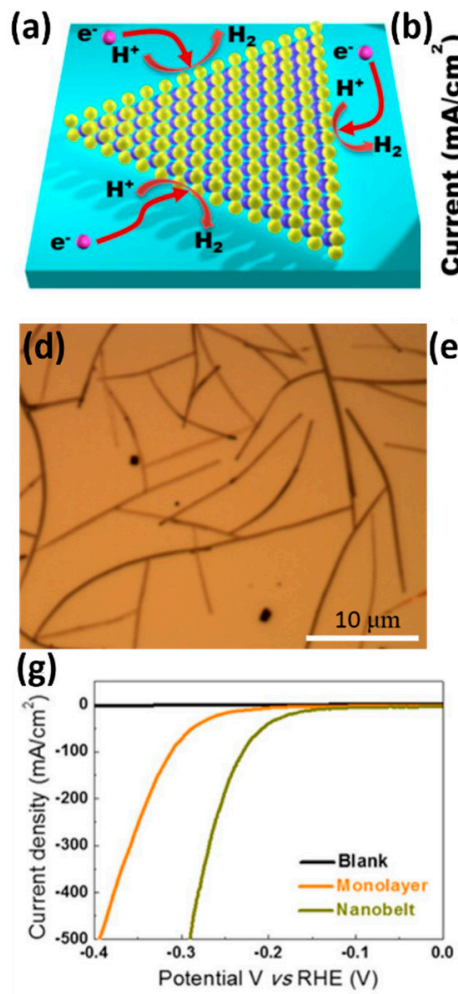

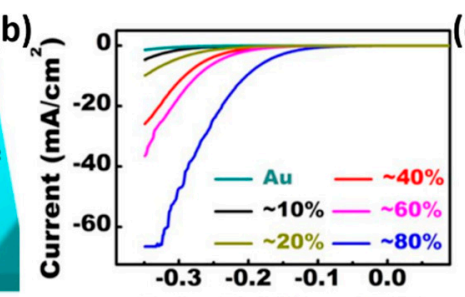

(e) Potential (V vs RHE)

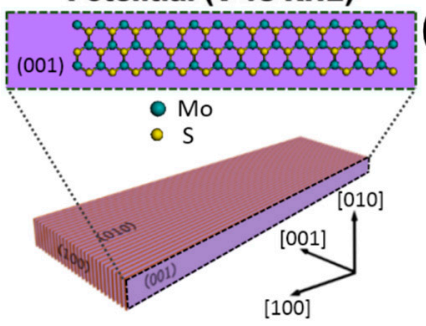

(h)

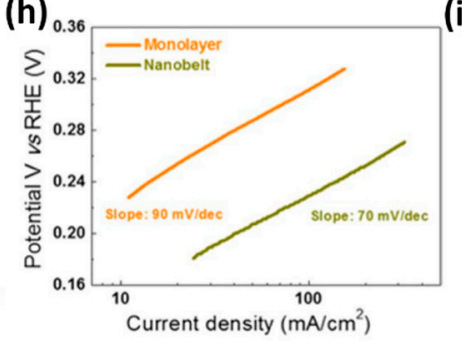

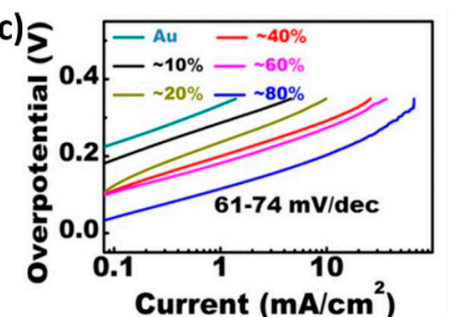

(f)

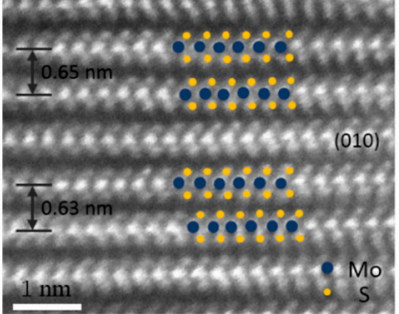

(i)

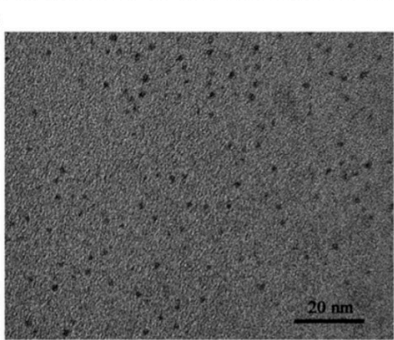

Figure 5. (a) Schematic illustration of the HER catalytic activity in the monolayer $\mathrm{MoS}_{2}$ [52]. (b) Polarization curves and (c) Tafel plots of monolayer $\mathrm{MoS}_{2}$ on Au foils with different coverage [52]. (d) Optical image of $\mathrm{MoS}_{2}$ nanobelts [53]. (e) Schematic illustration and (f) HRSTEM image of $\mathrm{MoS}_{2}$ nanobelts [53]. (g) Polarization curves and (h) Tafel plots of monolayer $\mathrm{MoS}_{2}$ and $\mathrm{MoS}_{2}$ nanobelts [53]. (i) TEM image of the $\mathrm{MoS}_{2}$ nanoparticles [54]. Reproduced from [52,53] with permission from American Chemical Society and [54] with permission from copyright 2013 The Royal Society of Chemistry. 


\subsection{Improving the Electrical Conductivity}

\subsubsection{Growing $\mathrm{MoS}_{2}$ on Conductive Carbon-Based Substrates}

Another factor that obstructs the catalytic performance of $\mathrm{MoS}_{2}$ is its poor electrical transport $[32,55]$. As we know, both bulk 2H- and $3 \mathrm{R}-\mathrm{MoS}_{2}$ are semiconductors with a band gap of $1.3 \mathrm{eV}$ [56]. In general, the high conductivity of the catalyst would increase the electron transport from the active sites to the electrodes. Thus, increasing the electrical transport behavior of $\mathrm{MoS}_{2}$ is an efficient way to enhance its electrocatalytic activity [57]. In 2011, Dai's group first reported the synthesis of $\mathrm{MoS}_{2}$ on reduced graphene oxide (rGO) sheets [58]. The resultant $\mathrm{MoS}_{2} / \mathrm{rGO}$ hybrid material has an abundance of small $\mathrm{MoS}_{2}$ nanoparticles dispersed on the surface of the conductive rGO nanosheets. The schematic structure and SEM images of the hybrid structure are shown in Figure $6 \mathrm{a}, \mathrm{b}$. Compared with pure $\mathrm{MoS}_{2}$ nanoparticles, the $\mathrm{MoS}_{2} / \mathrm{rGO}$ hybrid structure exhibited excellent HER activity: the overpotential was $\sim-100 \mathrm{mV}$ and the Tafel slope was $\sim 41 \mathrm{mV} / \mathrm{dec}$ (Figure $6 \mathrm{c}$ ). This was attributed to the excellent electrical coupling effect between the underlying graphene sheets and the rich active edge sites. Similarly, Liu's group synthesized a $\mathrm{MoS}_{2}$ / carbon nanotube (CNT) nanocomposite network by a facile solvothermal method. The SEM image of the $\mathrm{MoS}_{2}$ / CNT composite is shown in Figure 6d [59]. Similar to the graphene sheets, the CNT could also provide a rapid electron transport channel from the less conducting $\mathrm{MoS}_{2}$ to the electrodes. As a result, the $\mathrm{MoS}_{2} / \mathrm{CNT}$ network exhibited excellent electrocatalytic activity for the HER (a low onset potential of $-90 \mathrm{mV}$ and a low Tafel slope of $44.6 \mathrm{mV} / \mathrm{dec})$.
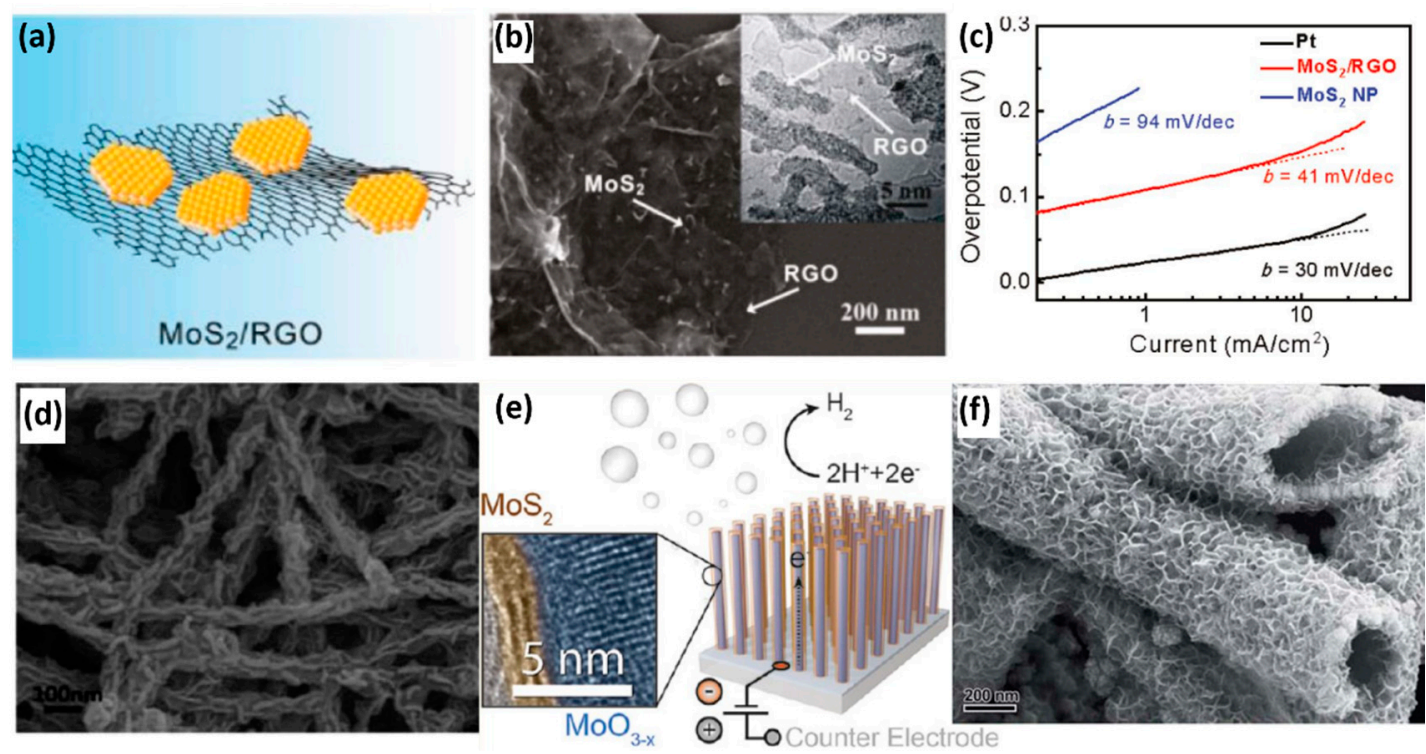

Figure 6. (a) Schematic illustration and (b) SEM image of the $\mathrm{MoS}_{2} / \mathrm{rGO}$ hybrid [58]. The inset in (b) is the corresponding TEM image. (c) Tafel plots of several catalysts with a loading of $0.28 \mathrm{mg} / \mathrm{cm}^{2}$ as indicated [58]. (d) SEM image of the $\mathrm{MoS}_{2} / \mathrm{CNT}$ composite [59]. (e) Left: HRTEM image of $\mathrm{MoO}_{3} / \mathrm{MoS}_{2}$ heterostructure. Right: schematic illustration of the HER catalytic activity in the $\mathrm{MoO}_{3} / \mathrm{MoS}_{2}$ heterostructure [60]. (f) SEM image of $\mathrm{MoS}_{2} / \mathrm{SnO}_{2}$ nanotube heterostructure [61]. Reproduced from [58,60] with permission from copyright 2011. American Chemical Society and [59,61] with permission from copyright The Royal Society of Chemistry.

\subsubsection{Fabricating $\mathrm{MoS}_{2}$-Based Heterostructures}

Besides the carbon-based substrates, a hybrid structure can also enhance the $\mathrm{MoS}_{2}$ HER performance [60-64]. Jaramillo's group designed vertically oriented core-shell $\mathrm{MoO}_{3} / \mathrm{MoS}_{2}$ heterostructure nanowires [60]. Figure 6e shows the scheme illustration and TEM image of the as-synthesized core/shell structure of $\mathrm{MoO}_{3} / \mathrm{MoS}_{2}$ nanowires. Experimental investigations 
indicated that the $\mathrm{MoO}_{3} / \mathrm{MoS}_{2}$ heterostructures exhibited enhanced HER activity: the overpotential was approximately $-200--150 \mathrm{mV}$, and the Tafel slope was 50-60 mV/dec. The $\mathrm{MoO}_{3}$ core with $\sim 20-50 \mathrm{~nm}$ enabled facile charge transport events, and the $\mathrm{MoS}_{2}$ shell $\sim 2-5 \mathrm{~nm}$ thick provided excellent catalytic activity. In addition, the stability of the catalyst is another important requirement for the HER application. There was no current degradation after 10,000 cycles in the stability test on $\mathrm{MoO}_{3} / \mathrm{MoS}_{2}$ heterostructures. The $\mathrm{MoS}_{2}$ shell could also serve as a protective layer during the HER process to keep the $\mathrm{MoO}_{3}$ away from the acidic environments. Huang et al. also tried the $\mathrm{SnO}_{2}$ as charge transport core by constructing a heterostructure of $\mathrm{SnO}_{2} / \mathrm{MoS}_{2}$ (Figure 6f) [61]. Similar to the $\mathrm{MoO}_{3} / \mathrm{MoS}_{2}$ heterostructures, the $\mathrm{SnO}_{2} / \mathrm{MoS}_{2}$ composite also exhibited excellent HER activity: a relatively low overpotential of $-150 \mathrm{mV}$, a small Tafel slope of $59 \mathrm{mV} / \mathrm{dec}$, and a large current density of $2.3 \mathrm{~mA} / \mathrm{cm}^{2}$ at $\eta=-150 \mathrm{mV}$.

Furthermore, Yu's group have synthesized a heterostructure of $\mathrm{CoSe}_{2} / \mathrm{MoS}_{2}$ (Figure 7a) by growing $\mathrm{MoS}_{2}$ on a $\mathrm{CoSe}_{2} / \mathrm{DETA}$ nanobelt substrate [65]. In an acidic electrolyte, the $\mathrm{CoSe}_{2} / \mathrm{MoS}_{2}$ hybrid structure exhibited the best HER activity among the non-noble metal hydrogen evolution catalysts with an onset potential of $-11 \mathrm{mV}$ and a Tafel slope of $36 \mathrm{mV} / \mathrm{dec}$ (Figure $7 \mathrm{~b}, \mathrm{c}$ ). The appreciation of the exceptional HER catalytic properties can be divided into four aspects. Firstly, the quasi-amorphous structure of $\mathrm{MoS}_{2}$ can increase the number of active edge sites in the $\mathrm{MoS}_{2} / \mathrm{CoSe}_{2}$ hybrid composite; secondly, the conductive $\mathrm{CoSe}_{2}$ can facilitate fast charge transport during the HER process; third, $\mathrm{CoSe}_{2}$ chemically interacted with $\mathrm{MoS}_{2}$ by forming a bond of S-Co that can further improve the HER activity of the heterostructure structure. Finally, the anchored $\mathrm{MoS}_{2}$ can also exert a positive effect on the reaction sites of $\mathrm{CoSe}_{2}$ and enhance the catalytic activity.
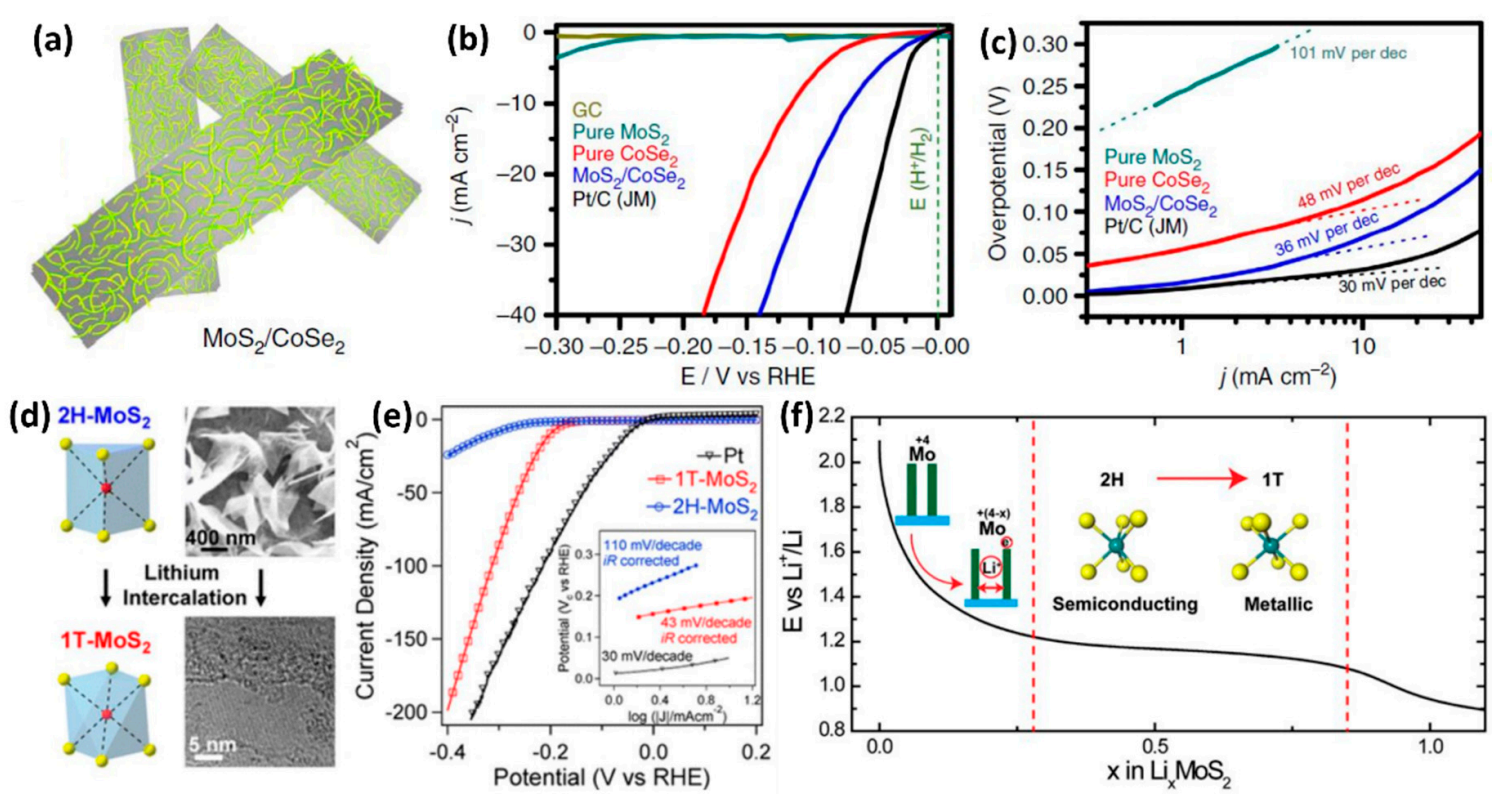

Figure 7. (a) Schematic illustration of $\mathrm{MoS}_{2} / \mathrm{CoSe}_{2}$ heterostructure [65]. (b) Polarization curves and (c) Tafel plots of $\mathrm{MoS}_{2} / \mathrm{CoSe}_{2}$ hybrid, pure $\mathrm{MoS}_{2}$, pure CoSe 2 , and Pt/C. Catalyst loading is about $0.28 \mathrm{mg} / \mathrm{cm}^{-2}$ [65]. (d) Top: the atomic models and SEM image of $2 \mathrm{H}-\mathrm{MoS}_{2}$. Bottom: the atomic models and HRTEM image of chemically exfoliated 1T-MoS ${ }_{2}$ nanosheets [66]. (e) Polarization curves and Tafel plots (insert figure) of chemically exfoliated 1T-MoS 2 and as-grown $2 \mathrm{H}-\mathrm{MoS}_{2}$ nanosheets [66]. (f) Galvanostatic discharge curve representing the lithiation process in $\mathrm{MoS}_{2}$ [67]. Reproduced from [65] with permission from copyright 2015 Nature Publishing Group, [66] with permission from copyright 2013 American Chemical Society, and [67] with permission from copyright 2013 Proceedings of the National Academy of Sciences of the United States of America. 


\subsubsection{HER in Conductive $\mathrm{MoS}_{2}$ Prepared via Lithium Intercalation}

It is well known that the hexagonal structure of $\mathrm{MoS}_{2}$ shows semiconducting behavior, while the trigonal structure of $\mathrm{MoS}_{2}$ shows metallic behavior [20]. Transferring $\mathrm{MoS}_{2}$ from the semiconductor phase to the metal phase may also decrease the charge transfer resistance, thus improving its catalytic performance. Jin's group reported the synthesis of metallic 1T-MoS nanosheets via lithium intercalation [66]. X-ray diffraction (XRD), Raman scattering, current-sensing atomic force microscopy, and HRTEM characterizations confirmed the formation of 1T-MoS after lithium intercalation. As expected, dramatically improved HER activities were achieved in the as-synthesized 1T- $\mathrm{MoS}_{2}$ nanosheets. The overpotential at a current density of $10 \mathrm{~mA} / \mathrm{cm}^{2}$ was $-187 \mathrm{mV}$ vs. RHE, and the Tafel slope was $43 \mathrm{mV} / \mathrm{dec}$ (Figure 7e). Similar results were also observed in the $1 \mathrm{~T}-\mathrm{WS}_{2}$ [3]. Cui's group also advanced this structure-tuning investigation by discharging $\mathrm{MoS}_{2}$ based on a Li-ion battery [67]. Firstly, they synthesized the $\mathrm{MoS}_{2}$ films with molecular layers perpendicular to the substrate, as mentioned in Section 3.2.3. Then the $\mathrm{MoS}_{2}$ nanofilms, utilized as a negative electrode, were assembled into a half-cell to continuously tune the amount of intercalated $\mathrm{Li}$ ions. Figure $7 \mathrm{f}$ shows the discharge curve, which represents the lithiation process. The electrochemical characterizations indicated that as the amount of $\mathrm{Li}$ increased from $x=0$ to $x=0.02$ and $x=0.07$, the Tafel slope decreased from $123 \mathrm{mV} / \mathrm{dec}$ to 84 and $60 \mathrm{mV} / \mathrm{dec}$. The improved HER performance was mainly due to the lower oxidation states of Mo, as confirmed by the X-ray photoelectron spectroscopy (XPS) spectra. The oxidation states of Mo are related to the electron filling of bonding and antibonding between the active sites and atomic hydrogen. As the oxidation states of Mo are lowered, it would change the hydrogen bonding energy and activation barrier, thus improve the HER activity. When increasing the amount of $\mathrm{Li}$ to $x=0.28$ and $x=0.85$, the HER catalytic activities were further improved. This was mainly due to a $2 \mathrm{H}-1 \mathrm{~T}$ phase transition in $\mathrm{MoS}_{2}$. The Tafel slopes in $x=0.28$ and $x=0.85$ were both saturated around $44 \mathrm{mV} / \mathrm{dec}$, similar to the results observed in the $1 \mathrm{~T}-\mathrm{MoS}_{2}$ sheets exfoliated by n-Butyl lithium.

\subsection{Optimizing the Electronic Structure of $\mathrm{MoS}_{2}$}

\subsubsection{Strain Effect}

As discussed in Section 3.3.2, the introduction of defects on the basal plane of $\mathrm{MoS}_{2}$ could enhance the HER catalytic performance. To further promote the activity, Zheng's group tried to exert strains on the $\mathrm{MoS}_{2}$ with S-vacancy [68]. According to the DFT calculations, some new bands appeared in the gap near the Fermi level in the $\mathrm{MoS}_{2}$ with S-vacancy. As a tensile strain was applied on the $\mathrm{MoS}_{2}$ with S-vacancy, these new bands moved closer to the Fermi level and the number of gap states increased. The increased gap states around the Fermi level favored the hydrogen adsorption on the S-vacancy sites, thus enhancing the HER activity. To confirm the calculations from the DFT, they first synthesized monolayer $2 \mathrm{H}-\mathrm{MoS}_{2}$ via CVD method by using $\mathrm{MoO}_{3}$ and $\mathrm{S}$ powders as the precursors. Then they applied a tensile strain via a patterned Au nanocone through a capillary force. They also created S-vacancies on the basal plane by treating the $\mathrm{MoS}_{2}$ with Ar plasma, where the density of the S-vacancies could be controlled by varying the exposing time. Figure 8a shows the schematic illustration of the HER catalytic activity in a strain-affected $\mathrm{MoS}_{2}$ with S-vacancy. By optimizing the combinations of strain effect and S-vacancies (such as 3.12\% S-vacancy with $8 \%$ strain and $12.5 \%$ S-vacancy with $1 \%$ strain), the $\mathrm{MoS}_{2}$ exhibited an excellent HER performance. The potential corresponding to $10 \mathrm{~mA} / \mathrm{cm}^{2}$ for the strained $\mathrm{MoS}_{2}$ with S-vacancy was $-170 \mathrm{mV}$, lower than that of unstrained $\mathrm{MoS}_{2}$ with S-vacancy $(-250 \mathrm{mV})$, the strained $\mathrm{MoS}_{2}$ without S-vacancy, as well as the transferred $\mathrm{MoS}_{2}$ (Figure 8b). The Tafel slope and the TOFs-vacancy (at $0 \mathrm{~V}$ versus RHE) for the strained $\mathrm{MoS}_{2}$ with S-vacancy were $60 \mathrm{mV} / \mathrm{dec}$ and $0.08-0.31 \mathrm{~s}^{-1}$, respectively, better than that of strained $\mathrm{MoS}_{2}$ without S-vacancy, the unstrained $\mathrm{MoS}_{2}$ with S-vacancy, as well as the transferred $\mathrm{MoS}_{2}$ (Figure 8c). 
(a)

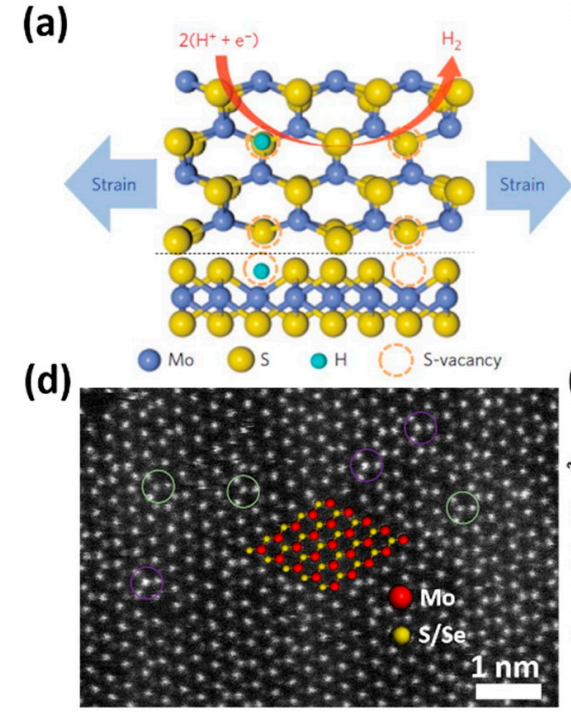

(b)

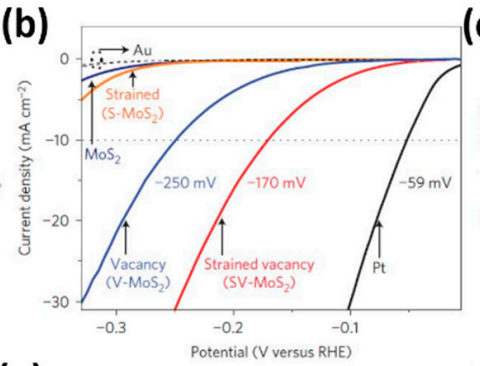

(e)

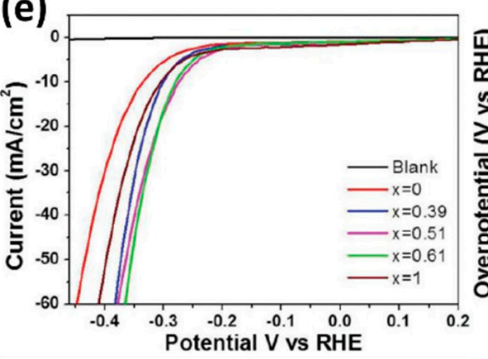

(c)
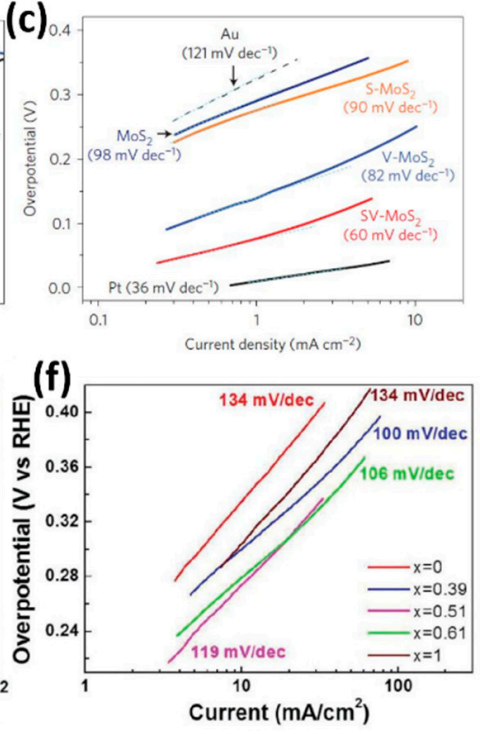

Figure 8. (a) Schematic of the top and side views of $\mathrm{MoS}_{2}$ with strained S-vacancies on the basal plane [68]. (b) Polarization curves and (c) Tafel plots of various $\mathrm{MoS}_{2}$ catalysts as indicated [68]. (d) HRSTEM image of monolayer $\mathrm{MoS}_{2(1-\mathrm{x})} \mathrm{Se}_{2 \mathrm{x}}$ alloy with $x=0.39$ [69]. (e) Polarization curves and (f) Tafel plots of monolayer $\mathrm{MoS}_{2(1-x)} \mathrm{Se}_{2 x}$ with different Se contents [69]. Reproduced from [68] with permission from copyright 2016 Nature Publishing Group and [69] with permission from copyright 2015 The Royal Society of Chemistry.

\subsubsection{Catalytic Performance in Alloy Structures}

Another efficient way to enhance the HER performance of $\mathrm{MoS}_{2}$ is to form $\mathrm{MoS}_{2}$-based alloys [69-73]. Our group synthesized monolayer $\mathrm{MoS}_{2(1-x)} \mathrm{Se}_{2 x}$ alloys and $\mathrm{MoS}_{2(1-x)} \mathrm{Se}_{2 x}$ nanobelt alloys via a CVD method by using $\mathrm{MoO}_{3}, \mathrm{~S}$ powder, and Se powder as reactants [69,73]. By adjusting the weight ratio of $S$ and Se powders, the monolayer $\mathrm{MoS}_{2(1-x)} \mathrm{Se}_{2 x}$ and $\mathrm{MoS}_{2(1-x)} \mathrm{Se}_{2 x}$ nanobelt alloys with different Se contents can be achieved. The HRSTEM image of monolayer $\mathrm{MoS}_{2(1-\mathrm{x})} \mathrm{Se}_{2 \mathrm{x}}$ alloys with $x=0.39$ (Figure 8d) indicated that some of the $S$ atoms were successfully replaced by Se atoms in the $\mathrm{MoS}_{2}$ lattice structure. Raman scattering and photoluminescence characterizations confirmed that the electronic structures could be tuned in the $\mathrm{MoS}_{2(1-x)} \mathrm{Se}_{2 x}$ alloys. The electrochemical catalytic activity characterizations indicated that in the monolayer $\operatorname{MoS}_{2(1-x)} \mathrm{Se}_{2 \mathrm{x}}$ alloys, the overpotential at the current density of $10 \mathrm{~mA} / \mathrm{cm}^{2}$ was $-300 \mathrm{mV}(x=0.39),-273 \mathrm{mV}(x=0.51)$ and $-279 \mathrm{mV}$ $(x=0.61)$, respectively. It showed smaller overpotential than that of pure monolayer $\mathrm{MoS}_{2}(-335 \mathrm{mV})$, as demonstrated in Figure 8e. The Tafel slope of monolayer $\operatorname{MoS}_{2(1-\mathrm{x})} \mathrm{Se}_{2 \mathrm{x}}(x=0.39,0.51,0.61)$ was $100 \mathrm{mV} / \mathrm{dec}, 119 \mathrm{mV} / \mathrm{dec}, 106 \mathrm{mV} / \mathrm{dec}$, respectively (Figure $8 \mathrm{f}$ ). Similar enhanced catalytic performance was also observed in the $\mathrm{MoS}_{2(1-x)} \mathrm{Se}_{2 x}$ nanobelt alloys [73]. The Gibbs free energy of hydrogen adsorption for a catalyst is strongly related to the density of states near the Fermi level. As the density of states near Fermi level increased, reduced $\Delta \mathrm{G}_{\mathrm{H}}$ can be achieved. Compared with pure $\mathrm{MoS}_{2}$, the Mo in $\mathrm{MoS}_{2(1-\mathrm{x})} \mathrm{Se}_{2 \mathrm{x}}$ alloys possesses a lower oxidation state. As a result, a more negative hydrogen adsorption energy can be achieved. Therefore, enhanced HER activities are achieved in the $\mathrm{MoS}_{2(1-\mathrm{x})} \mathrm{Se}_{2 \mathrm{x}}$ alloys compared with pure $\mathrm{MoS}_{2}$. A similar trend was also observed in the $\mathrm{WS}_{2(1-\mathrm{x})} \mathrm{Se}_{2 \mathrm{x}}$ alloys system [74]. We summarize the HER performance of a variety of $\mathrm{MoS}_{2}$ catalysts mentioned above in Table 1. 
Table 1. Onset overpotentials, overpotentials $\cong 10 \mathrm{~mA} / \mathrm{cm}^{2}$, Tafel slopes, and exchange current densities of different $\mathrm{MoS}_{2}$ catalysts.

\begin{tabular}{|c|c|c|c|c|}
\hline Catalyst & $\begin{array}{c}\text { Onset } \\
\text { Overpotential }(\mathrm{mV})\end{array}$ & $\begin{array}{c}\text { Overpotential } \\
\cong 10 \mathrm{~mA} / \mathrm{cm}^{2}(\mathrm{mV})\end{array}$ & $\begin{array}{l}\text { Tafel Slope } \\
\text { (mV/dec) }\end{array}$ & $\begin{array}{c}\text { Exchange Current } \\
\text { Densities } j_{0} \\
\left(\mu \mathrm{A} / \mathrm{cm}^{2}\right)\end{array}$ \\
\hline Co-doped $\mathrm{MoS}_{2}$ nanoparticle & - & -400 & 101 & - \\
\hline Transition metal-doped $\mathrm{MoS}_{2}$ nanofilms & - & - & $107-118$ & $2.2-4.9$ \\
\hline Amorphous $\mathrm{MoS}_{2}$ & -165 & - & 47 & 0.027 \\
\hline Defect-rich ultrathin $\mathrm{MoS}_{2}$ nanosheets & -120 & $\sim-190$ & 50 & 8.91 \\
\hline $\begin{array}{c}\text { Disordered oxygen-incorporated } \mathrm{MoS}_{2} \\
\text { nanosheets }\left(140^{\circ} \mathrm{C}\right)\end{array}$ & - & $\sim-210$ & 67 & 5.6 \\
\hline Plasma-engineered $\mathrm{MoS}_{2}$ thin films & - & $\sim-300$ & 105 & - \\
\hline $\begin{array}{c}\mathrm{MoS}_{2} \text { thin films with vertically aligned } \\
\text { layers }\end{array}$ & - & - & $105-120$ & 2.2 \\
\hline $\mathrm{MoS}_{2}$ films with double-gyroid morphology & $-200--150$ & $\sim-220$ & 50 & 0.69 \\
\hline Monolayer $\mathrm{MoS}_{2}$ & -100 & $\sim-210$ & 61 & 38.1 \\
\hline $\mathrm{MoS}_{2}$ nanobelts & -170 & -140 & 70 & - \\
\hline $\mathrm{MoS}_{2}$ nanoparticles & -90 & $\sim-220$ & 69 & 9.3 \\
\hline $\mathrm{MoS}_{2} / \mathrm{rGO}$ & -100 & $\sim-155$ & 41 & - \\
\hline $\mathrm{MoS}_{2} / \mathrm{CNT}$ & -90 & $\sim-180$ & 44.6 & - \\
\hline $\mathrm{MoO}_{3} / \mathrm{MoS}_{2}$ heterostructure & $-200--150$ & $\sim-250$ & $50-60$ & - \\
\hline $\mathrm{SnO}_{2} / \mathrm{MoS}_{2}$ heterostructure & -150 & $\sim-220$ & 59 & - \\
\hline $\mathrm{CoSe}_{2} / \mathrm{MoS}_{2}$ heterostructure & -11 & $\sim-70$ & 36 & 73 \\
\hline $1 \mathrm{~T}-\mathrm{MoS}_{2}$ nanosheets & - & -187 & 43 & - \\
\hline Strained $\mathrm{MoS}_{2}$ with S-vacancies & - & -170 & 60 & - \\
\hline $\mathrm{MoS}_{2(1-x)} \mathrm{Se}_{2 x}$ nanobelts alloys & -139 & - & 65 & - \\
\hline
\end{tabular}

\subsection{Some New Results}

More interestingly, contrary to the traditional view that the number of edge sites is important, some studies also point out that the hopping efficiency of electrons in the vertical direction or the resistance plays a key role in the development of high-efficiency two-dimensional material catalysts [75-77]. Cao et al. have investigated layer-dependent $\mathrm{MoS}_{2}$ electrocatalytic activity by controlling the number of layers during the synthesis [76]. The polarization curves of monolayer, bilayer, and trilayer $\mathrm{MoS}_{2}$ films are shown in Figure 9a. Different from the previous study's results suggesting that more active sites means higher electrocatalytic activity, the electrochemical characterizations indicated that the exchange current density decreased by a factor of $\sim 4.47$ with the addition of every layer. During the HER process, the electrochemical reaction only occurs at the outmost layer of the $\mathrm{MoS}_{2}$ film, and the electrons have to transfer from the glassy carbon electrode to the outermost layer [76]. As the potential barriers exit in the interlayer gap, the electron transfer in the perpendicular direction is through hopping (Figure 9b), which makes the thicker sample shows poor electrocatalytic performance. Recently, Shin's group also investigated the electrocatalytic performance of $\mathrm{MoS}_{2}$ with a different number of edge sites [77]. Their experimental results indicated that the thicker zone with the maximum number of edge sites did not exhibit the best HER performance, while the thin zone consisting of basal planes resulted in the best performance. They attributed the low HER performance to the higher material resistance in the thicker layers, thereby limiting electron transfer for the HER. Therefore, strategies that can increase the electrons' hopping efficiency in the vertical direction or lower the resistance are expected to be able to enhance the electrocatalytic performance of $\mathrm{MoS}_{2}$ materials. 
(a)

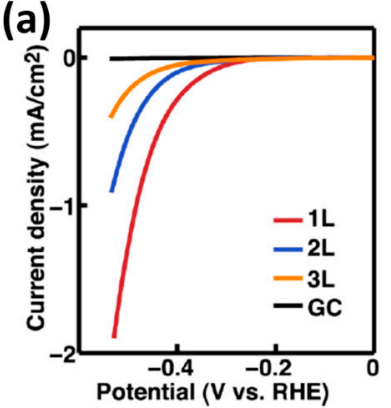

(c)

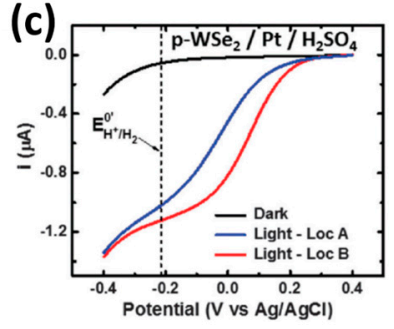

(b)

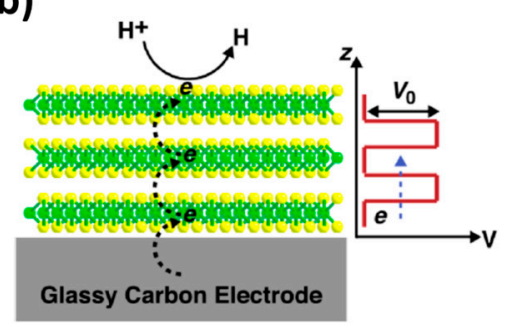

(d)

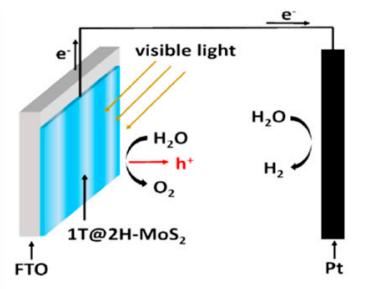

Figure 9. (a) Polarization curves of the monolayer (red, $1 \mathrm{~L}$ ), bilayer (blue, $2 \mathrm{~L}$ ), and trilayer (orange, $3 \mathrm{~L}$ ) $\mathrm{MoS}_{2}$ films [76]; (b) Hopping of electrons in the vertical direction of $\mathrm{MoS}_{2}$ layers [76]; (c) Linear sweep voltammograms of $\mathrm{p}-\mathrm{MoS}_{2} / \mathrm{Pt}$ obtained with and without laser beam irradiation, respectively [78]; (d) Schematic representation of photoelectrochemical cells with $1 \mathrm{~T}-2 \mathrm{H}-\mathrm{MoS}_{2}$ on FTO as photoanode [79]. Reproduced from [76,79] with permission from copyright American Chemical Society and [78] with permission from copyright 2016 The Royal Society of Chemistry.

\section{The Photoelectrocatalytic HER}

Besides the electrocatalysis, the application of photoelectrocatalytic HER of TMDs has also been investigated. The semiconducting TMDs have an indirect band gap of $1.0 \mathrm{eV}$ to $1.5 \mathrm{eV}$, and a direct band gap of $1.4 \mathrm{eV}$ to $2.3 \mathrm{eV}$ [78-82]. When the photon energies are above the indirect and direct band gap, the TMDs will absorb the photon and show large absorption coefficients $\left(\approx 10^{5} \mathrm{~cm}^{-1}\right.$ and $\approx 10^{6} \mathrm{~cm}^{-1}$, respectively) [78-82]. For example, the $\mathrm{WSe}_{2}$ material shows high absorption with near-unity absorption peak occurring between 500 and $650 \mathrm{~nm}$ [79]. Fabricating TMDs/metal heterostructures is an effective way to further enhance their light absorption due to an increase in the local density of states (LDOS) near the semiconductor/metal interface [79-81]. The high light absorption combined with the active electrocatalytic performance make the semiconducting TMDs an excellent photoelectrocatalyst [78-81]. Lewis's group investigated the photoelectrochemical performance of Pt-decorated p-type $\mathrm{WSe}_{2}$ photocathodes by using scanning photocurrent microscopy [78]. The linear sweep voltammograms indicated that the photocurrent increased markedly when the laser beam was irradiated on the Pt-decorated p-type $\mathrm{WSe}_{2}$ photocathodes (Figure 9c). For the $\mathrm{MoS}_{2}$, the metallic 1T phase possesses higher photoelectrocatalytic activity because it can serve as a good electron acceptor and transporter material [79]. Faster electron transport can effectively suppress the recombination processes of photogenerated charges and thus enhance photocatalytic activity under visible light. Chen's group has proposed a strategy to efficiently increase the concentration of the $1 \mathrm{~T}$ phase in exfoliated two-dimensional $\mathrm{MoS}_{2}$ nanosheets by using $\mathrm{SC} \mathrm{CO}_{2}$-induced phase engineering [79]. As expected, the photocurrent of $1 \mathrm{~T}-2 \mathrm{H} \mathrm{MoS} \mathrm{S}_{2}$-based photoelectrochemical cells (Figure 9d) at $-0.6 \mathrm{~V}$ was $-1400 \mu \mathrm{A} / \mathrm{cm}^{2}$, much higher than that of pure $2 \mathrm{H} \mathrm{MoS} 2\left(-400 \mu \mathrm{A} / \mathrm{cm}^{2}\right)$.

\section{Summary and Outlook}

This review has summarized the recent developments of nanostructured $\mathrm{MoS}_{2}$ as electrocatalysts for hydrogen evolution. Specifically, activating the inert edge sites, improving the electrical conductivity, and optimizing the electronic structure are the main strategies to effectively enhance 
the electrocatalytic efficiency of $\mathrm{MoS}_{2}$. The excellent HER performance makes $\mathrm{MoS}_{2}$ a highly promising candidate to replace conventional noble-metal-based catalysts. However, there are still some issues to be solved before using these materials in industry. The first is the stability of $\mathrm{MoS}_{2}$ catalysts. The industrial applications of a catalyst should have long-term stability, not limited to several tens of hours, as demonstrated in the lab. The second challenge is the production cost and scalability. Even though $\mathrm{MoS}_{2}$ is an abundant material and can be synthesized from relatively abundant materials, reducing the cost is still important for $\mathrm{MoS}_{2}$ large-scale applications. In the end, further improving the electrocatalytic performance of $\mathrm{MoS}_{2}$ remains challenging. Although $\mathrm{MoS}_{2}$-based catalysts have exhibited excellent activities, their HER electrochemical catalytic activity is still unable to surpass that of the noble metals.

Acknowledgments: This work was supported by the Research Foundation for Young Talents of West Anhui University, the joint fund of the National Natural Science Foundation Committee of China Academy of Engineering Physics (NSAF) (U1630108) and the National Natural Science Foundation of China $(21373196,11434009)$. This work was partially carried out at the USTC Center for Micro and Nanoscale Research and Fabrication.

Author Contributions: Lei Yang and Bin Xiang contributed to the conception and the writing of this paper. Ping Liu and Jing Li contributed to the revision of this paper.

Conflicts of Interest: The authors declare no conflict of interest.

\section{References}

1. Cheng, Q.; Song, Z.; Ma, T.; Smith, B.B.; Tang, R.; Yu, H.; Jiang, H.; Chan, C.K. Folding paper-based lithium-ion batteries for higher areal energy densities. Nano Lett. 2013, 13, 4969-4974. [CrossRef] [PubMed]

2. Wang, Y.; Wang, Q.; Zhan, X.; Wang, F.; Safdar, M.; He, J. Visible light driven type II heterostructures and their enhanced photocatalysis properties: A review. Nanoscale 2013, 5, 8326-8339. [CrossRef] [PubMed]

3. Lukowski, M.A.; Daniel, A.S.; English, C.R.; Meng, F.; Forticaux, A.; Hamers, R.J.; Jin, S. Highly active hydrogen evolution catalysis from metallic WS2 nanosheets. Energy Environ. Sci. 2014, 7, $2608-2613$. [CrossRef]

4. Chamberlain, G.A. Organic solar cells: A review. Sol. Cells 1983, 8, 47-83. [CrossRef]

5. Cortright, R.D.; Davda, R.R.; Dumesic, J.A. Hydrogen from catalytic reforming of biomass-derived hydrocarbons in liquid water. Nature 2002, 418, 964-967. [CrossRef] [PubMed]

6. Gewirth, A.A.; Thorum, M.S. Electroreduction of dioxygen for fuel-cell applications: Materials and challenges. Inorg. Chem. 2010, 49, 3557-3566. [CrossRef] [PubMed]

7. Jiao, Y.; Zheng, Y.; Jaroniec, M.; Qiao, S.Z. Design of electrocatalysts for oxygen- and hydrogen-involving energy conversion reactions. Chem. Soc. Rev. 2015, 44, 2060-2086. [CrossRef] [PubMed]

8. Greeley, J.; Jaramillo, T.F.; Bonde, J.; Chorkendorff, I.; Nørskov, J.K. Computational high-throughput screening of electrocatalytic materials for hydrogen evolution. Nat. Mater. 2006, 5, 909-913. [CrossRef] [PubMed]

9. Okamoto, Y.; Ida, S.; Hyodo, J.; Hagiwara, H.; Ishihara, T. Synthesis and photocatalytic activity of rhodium-doped calcium niobate nanosheets for hydrogen production from a water/methanol system without cocatalyst loading. J. Am. Chem. Soc. 2011, 133, 18034-18037. [CrossRef] [PubMed]

10. Merki, D.; Hu, X. Recent developments of molybdenum and tungsten sulfides as hydrogen evolution catalysts. Energy Environ. Sci. 2011, 4, 3878-3888. [CrossRef]

11. Helm, M.L.; Stewart, M.P.; Bullock, R.M.; DuBois, M.R.; DuBois, D.L. A synthetic nickel electrocatalyst with a turnover frequency above 100,000 s $\mathrm{s}^{-1}$ for H2 production. Science 2011, 333, 863-866. [CrossRef] [PubMed]

12. Norskov, J.K.; Christensen, C.H. Toward efficient hydrogen production at surfaces. Science 2006, 312, 1322-1323. [CrossRef] [PubMed]

13. Pletcher, D. Electrocatalysis: Present and future. J. Appl. Electrochem. 1984, 14, 403-415. [CrossRef]

14. Yang, Z.; Zhang, J.; Kintner-Meyer, M.C.; Lu, X.; Choi, D.; Lemmon, J.P.; Liu, J. Electrochemical energy storage for green grid. Chem. Rev. 2011, 111, 3577-3613. [CrossRef] [PubMed]

15. Vesborg, P.C.K.; Jaramillo, T.F. Addressing the terawatt challenge: Scalability in the supply of chemical elements for renewable energy. RSC Adv. 2012, 2, 7933-7947. [CrossRef]

16. Manzeli, S.; Ovchinnikov, D.; Pasquier, D.; Yazyev, O.V.; Kis, A. 2D transition metal dichalcogenides. Nat. Rev. Mater. 2017, 2, 17033. [CrossRef] 
17. Tan, C.; Zhang, H. Two-dimensional transition metal dichalcogenide nanosheet-based composites. Chem. Soc. Rev. 2015, 44, 2713-2731. [CrossRef] [PubMed]

18. Ganatra, R.; Zhang, Q. Few-layer MoS2: A promising layered semiconductor. ACS Nano 2014, 8, 4074-4099. [CrossRef] [PubMed]

19. Seh, Z.W.; Kibsgaard, J.; Dickens, C.F.; Chorkendorff, I.; Nørskov, J.K.; Jaramillo, T.J. Combining theory and experiment in electrocatalysis: Insights into materials design. Science 2017, 355, 146. [CrossRef] [PubMed]

20. Chhowalla, M.; Shin, H.S.; Eda, G.; Li, L.-J.; Loh, K.P.; Zhang, H. The chemistry of two-dimensional layered transition metal dichalcogenide nanosheets. Nat. Chem. 2013, 5, 263-275. [CrossRef] [PubMed]

21. Lu, Q.; Yu, Y.; Ma, Q.; Chen, B.; Zhang, H. 2D transition-metal-dichalcogenide-nanosheet-based composites for photocatalytic and electrocatalytic. Adv. Mater. 2016, 28, 1917-1933. [CrossRef] [PubMed]

22. Sun, Y.; Gao, S.; Lei, F.; Xie, Y. Atomically-thin two-dimensional sheets for understanding active sites in catalysis. Chem. Soc. Rev. 2015, 44, 623-636. [CrossRef] [PubMed]

23. Velazquez, J.M.; Saadi, F.H.; Pieterick, A.P.; Spurgeon, J.M.; Soriaga, M.P.; Brunschwig, B.S.; Lewis, N.S. Synthesis and hydrogen-evolution activity of tungsten selenide thin films deposited on tungsten foils. J. Electroanal. Chem. 2014, 716, 45-48. [CrossRef]

24. Hinnemann, B.; Moses, P.G.; Bonde, J.; Jørgensen, K.P.; Nielsen, J.H.; Horch, S.; Chorkendorff, I.; Nørskov, J.K. Biomimetic hydrogen evolution: $\mathrm{MoS}_{2}$ nanoparticles as catalyst for hydrogen evolution. J. Am. Chem. Soc. 2005, 127, 5308-5309. [CrossRef] [PubMed]

25. Jaramillo, T.F.; Jørgensen, K.P.; Bonde, J.; Nielsen, J.H.; Horch, S.; Chorkendorff, I. Identification of active edge sites for electrochemical $\mathrm{H}_{2}$ evolution from $\mathrm{MoS}_{2}$ nanocatalysts. Science 2007, 317, 100-102. [CrossRef] [PubMed]

26. Appel, A.M.; DuBois, D.L.; DuBois, M.R. Molybdenum-Sulfur dimers as electrocatalysts for the production of hydrogen at low overpotentials. J. Am. Chem. Soc. 2005, 127, 12717-12726. [CrossRef] [PubMed]

27. Vesborg, P.C.K.; Seger, B.; Chorkendorff, I. Recent development in hydrogen evolution reaction catalysts and their practical implementation. J. Phys. Chem. Lett. 2015, 6, 951-957. [CrossRef] [PubMed]

28. Shia, Y.; Zhang, B. Recent advances in transition metal phosphide nanomaterials: Synthesis and applications in hydrogen evolution reaction. Chem. Soc. Rev. 2016, 45, 1529-1541. [CrossRef] [PubMed]

29. Voiry, D.; Yamaguchi, H.; Li, J.; Silva, R.; Alves, D.C.B.; Fujita, T.; Chen, M.; Asefa, T.; Shenoy, V.B.; Eda, G.; Chhowalla, M. Enhanced catalytic activity in strained chemically exfoliated $\mathrm{WS}_{2}$ nanosheets for hydrogen evolution. Nat. Mater. 2013, 12, 850-855. [CrossRef] [PubMed]

30. Parson, R. The rate of electrolytic hydrogen evolution and the heat of adsorption of hydrogen. Trans. Faraday Soc. 1958, 54, 1053-1063. [CrossRef]

31. Kam, K.K.; Parklnclon, B.A. Detailed photocurrent spectroscopy of the semiconducting group VIB transition metal dichaicogenldes. J. Phys. Chem. 1982, 86, 463-467. [CrossRef]

32. Laursen, A.B.; Kegnæs, S.; Dahla, S.; Chorkendorffa, I. Molybdenum sulfides-Efficient and viable materials for electro- and photoelectrocatalytic hydrogen evolution. Energy Environ. Sci. 2012, 5, 5577-5591. [CrossRef]

33. Helveg, S.; Lauritsen, J.V.; Lægsgaard, E.; Stensgaard, I.; Nørskov, J.K.; Clausen, B.S.; Topsøe, H.; Besenbacher, F. Atomic-scale structure of single-layer $\mathrm{MoS}_{2}$ nanoclusters. Phys. Rev. Lett. 2000, 84, 951-954. [CrossRef] [PubMed]

34. Lauritsen, J.V.; Kibsgaard, J.; Helveg, S.; Topsøe, H.; Clausen, B.S.; Lægsgaard, E.; Besenbacher, F. Size-dependent structure of $\mathrm{MoS}_{2}$ nanocrystals. Nat. Nanotechnol. 2007, 2, 53-58. [CrossRef] [PubMed]

35. Yang, J.; Shin, H.S. Recent advances in layered transition metal dichalcogenides for hydrogen evolution reaction. J. Mater. Chem. A 2014, 2, 5979-5985. [CrossRef]

36. Bonde, J.; Moses, P.G.; Jaramillo, T.F.; Nørskovb, J.K.; Chorkendorff, I. Hydrogen evolution on nano-particulate transition metal sulfides. Faraday Discuss 2008, 140, 219-231. [CrossRef] [PubMed]

37. Lu, Z.; Zhu, W.; Yu, X.; Zhang, H.; Li, Y.; Sun, X.; Wang, X.; Wang, H.; Wang, J.; Luo, J.; Lei, X.; Jiang, L. Ultrahigh hydrogen evolution performance of under-water "superaerophobic" $\mathrm{MoS}_{2}$ nanostructured electrodes. Adv. Mater. 2014, 26, 2683-2687. [CrossRef] [PubMed]

38. Tan, Y.W.; Liu, P.; Chen, L.Y.; Cong, W.T.; Ito, Y.; Han, J.H.; Guo, X.W.; Tang, Z.; Fujita, T.; Hirata, A.; et al. Monolayer $\mathrm{MoS}_{2}$ films supported by 3D nanoporous metals for high-effi ciency electrocatalytic hydrogen production. Adv. Mater. 2014, 26, 8023-8028. [CrossRef] [PubMed] 
39. Lee, Y.-H.; Zhang, X.-Q.; Zhang, W.; Chang, M.-T.; Lin, C.-T.; Chang, K.-D.; Yu, Y.-C.; Wang, J.T.-W.; Chang, C.-S.; Li, L.-J.; et al. Synthesis of large-area $\mathrm{MoS}_{2}$ atomic layers with chemical vapor deposition. Adv. Mater. 2012, 24, 2320-2325. [CrossRef] [PubMed]

40. Hansen, L.P.; Ramasse, Q.M.; Kisielowski, C.; Brorson, M.; Johnson, E.; Topsøe, H.; Helveg, S. Atomic-scale edge structures on industrial-style $\mathrm{MoS}_{2}$ nanocatalysts. Angew. Chem. Int. Ed. 2011, 50, 10153-10156. [CrossRef] [PubMed]

41. Kisielowski, C.; Ramasse, Q.M.; Hansen, L.P.; Brorson, M.; Carlsson, A.; Molenbroek, A.M.; Topsøe, H.; Helveg, S. Imaging $\mathrm{MoS}_{2}$ nanocatalysts with single-atom sensitivity. Angew. Chem. 2010, 122, 2768-2770. [CrossRef]

42. Tsai, C.; Abild-Pedersen, F.; Nørskov, J.K. Tuning the $\mathrm{MoS}_{2}$ edge-site activity for hydrogen evolution via support interactions. Nano Lett. 2014, 14, 1381-1387. [CrossRef] [PubMed]

43. Wang, H.; Tsai, C.; Kong, D.; Chan, K.; Abild-Pedersen, F.; Nørskov, J.K.; Cui, Y. Transition-metal doped edge sites in vertically aligned $\mathrm{MoS}_{2}$ catalysts for enhanced hydrogen evolution. Nano Res. 2015, 8, 566-575. [CrossRef]

44. Merki, D.; Fierro, S.; Vrubel, H.; Hu, X. Amorphous molybdenum sulfide films as catalysts for electrochemical hydrogen production in water. Chem. Sci. 2011, 2, 1262-1267. [CrossRef]

45. Shin, S.; Jin, Z.; Kwon, D.H.; Bose, R.; Min, Y.-S. High turnover frequency of hydrogen evolution reaction on amorphous $\mathrm{MoS}_{2}$ thin film directly grown by atomic layer deposition. Langmuir 2015, 31, 1196-1202. [CrossRef] [PubMed]

46. Xie, J.; Zhang, H.; Li, S.; Wang, R.; Sun, X.; Zhou, M.; Zhou, J.; Lou (David), X.W.; Xie, Y. Defect-rich MoS ultrathin nanosheets with additional active edge sites for enhanced electrocatalytic hydrogen evolution. Adv. Mater. 2013, 25, 5807-5813. [CrossRef] [PubMed]

47. Xie, J.; Zhang, J.; Li, S.; Grote, F.; Zhang, X.; Zhang, H.; Wang, R.; Lei, Y.; Pan, B.; Xie, Y. Controllable disorder engineering in oxygen-incorporated $\mathrm{MoS}_{2}$ ultrathin nanosheets for efficient hydrogen evolution. J. Am. Chem. Soc. 2013, 135, 17881-17888. [CrossRef] [PubMed]

48. Tao, L.; Duan, X.; Wang, C.; Duan, X.; Wang, S. Plasma-engineered $\mathrm{MoS}_{2}$ thin-film as an efficient electrocatalyst for hydrogen evolution reaction. Chem. Commun. 2015, 51, 7470-7473. [CrossRef] [PubMed]

49. Ye, G.; Gong, Y.; Lin, J.; Li, B.; He, Y.; Pantelides, S.T.; Zhou, W.; Vajtai, R.; Ajayan, P.M. Defects engineered monolayer $\mathrm{MoS}_{2}$ for improved hydrogen evolution reaction. Nano Lett. 2016, 16, 1097-1103. [CrossRef] [PubMed]

50. Kong, D.; Wang, H.; Cha, J.J.; Pasta, M.; Koski, K.J.; Yao, J.; Cui, Y. Synthesis of MoS 2 and MoSe 2 films with vertically aligned layers. Nano Lett. 2013, 13, 1341-1347. [CrossRef] [PubMed]

51. Kibsgaard, J.; Chen, Z.; Reinecke, B.N.; Jaramillo, T.F. Engineering the surface structure of $\mathrm{MoS}_{2}$ to preferentially expose active edge sites for electrocatalysis. Nat. Mater. 2012, 11, 963-969. [CrossRef] [PubMed]

52. Shi, J.; Ma, D.; Han, G.-F.; Zhang, Y.; Ji, Q.; Gao, T.; Sun, J.; Song, X.; Li, C.; Zhang, Y.; et al. Controllable growth and transfer of monolayer $\mathrm{MoS}_{2}$ on au foils and its potential application in hydrogen evolution reaction. ACS Nano 2014, 8, 10196-10204. [CrossRef] [PubMed]

53. Yang, L.; Hong, H.; Fu, Q.; Huang, Y.; Zhang, J.; Cui, X.; Fan, Z.; Liu, K.; Xiang, B. Single-crystal atomic-layered molybdenum disulfide nanobelts with high surface activity. ACS Nano 2015, 9, 6478-6483. [CrossRef] [PubMed]

54. Wang, T.; Liu, L.; Zhu, Z.; Papakonstantinou, P.; Hu, J.; Liu, H.; Li, M. Enhanced electrocatalytic activity for hydrogen evolution reaction from self-assembled monodispersed molybdenum sulfide nanoparticles on an Au electrode. Energy Environ. Sci. 2013, 6, 625-633. [CrossRef]

55. Ge, P.; Scanlon, M.D.; Peljo, P.; Bian, X.; Vubrel, H.; O’Neill, A.; Coleman, J.N.; Cantoni, M.; Hu, X.; Kontturi, K.; Liu, B.H.; Girault, H.H. Hydrogen evolution across nano-Schottky junctions at carbon supported $\mathrm{MoS}_{2}$ catalysts in biphasic liquid systems. Chem. Commun. 2012, 48, 6484-6486. [CrossRef] [PubMed]

56. Splendiani, A.; Sun, L.; Zhang, Y.; Li, T.; Kim, J.; Chim, C.-H.; Galli, G.; Wang, F. Emerging photoluminescence in monolayer $\mathrm{MoS}_{2}$. Nano Lett. 2010, 10, 1271-1275. [CrossRef] [PubMed]

57. Deng, Z.H.; Li, L.; Ding, W.; Xiong, K.; Wei, Z.D. Synthesized ultrathin $\mathrm{MoS}_{2}$ nanosheets perpendicular to graphene for catalysis of hydrogen evolution reaction. Chem. Commun. 2015, 51, 1893-1896. [CrossRef] [PubMed] 
58. Li, Y.; Wang, H.; Xie, L.; Liang, Y.; Hong, G.; Dai, H. MoS 2 nanoparticles grown on graphene: An advanced catalyst for the hydrogen evolution reaction. J. Am. Chem. Soc. 2011, 133, 7296-7299. [CrossRef] [PubMed]

59. Yan, Y.; Ge, X.; Liu, Z.; Wang, J.-Y.; Leea, J.-M.; Wang, X. Facile synthesis of low crystalline $\mathrm{MoS}_{2}$ nanosheet-coated CNTs for enhanced hydrogen evolution reaction. Nanoscale 2013, 5, 7768-7771. [CrossRef] [PubMed]

60. Chen, Z.; Cummins, D.; Reinecke, B.N.; Clark, E.; Sunkara, M.K.; Jaramillo, T.F. Core-shell $\mathrm{MoO}_{3}-\mathrm{MoS}_{2}$ nanowires for hydrogen evolution: A functional design for electrocatalytic materials. Nano Lett. 2011, 11, 4168-4175. [CrossRef] [PubMed]

61. Huang, Y.; Miao, Y.-E.; Zhang, L.; Tjiu, W.W.; Panb, J.; Liu, T. Synthesis of few-layered MoS 2 nanosheet-coated electrospun $\mathrm{SnO}_{2}$ nanotube heterostructures for enhanced hydrogen evolution reaction. Nanoscale 2014, 6, 10673-10679. [CrossRef] [PubMed]

62. Yang, L.; Zhou, W.; Hou, D.; Zhou, K.; Li, G.; Tang, Z.; Li, L.; Chen, S. Porous metallic $\mathrm{MoO}_{2}$-supported $\mathrm{MoS}_{2}$ nanosheets for enhanced electrocatalytic activity in the hydrogen evolution reaction. Nanoscale 2015, 7, 5203-5208. [CrossRef] [PubMed]

63. Li, D.J.; Maiti, U.N.; Lim, J.; Choi, D.S.; Lee, W.J.; Oh, Y.; Lee, G.Y.; Kim, S.O. Molybdenum sulfide/N-doped CNT forest hybrid catalysts for high-performance hydrogen evolution reaction. Nano Lett. 2014, 14, 1228-1233. [CrossRef] [PubMed]

64. Nikam, R.D.; Lu, A.-Y.; Sonawane, P.A.; Kumar, R.; Yadav, K.; Li, L.-J.; Chen, Y.-T. Three-dimensional heterostructures of $\mathrm{MoS}_{2}$ nanosheets on conducting $\mathrm{MoO}_{2}$ as an efficient electrocatalyst to enhance hydrogen evolution reaction. ACS Appl. Mater. Interfaces 2015, 7, 23328-23335. [CrossRef] [PubMed]

65. Gao, M.R.; Liang, J.X.; Zheng, Y.-R.; Xu, Y.-F.; Jiang, J.; Gao, Q.; Li, J.; Yu, S.-H. An efficient molybdenum disulfide/cobalt diselenide hybrid catalyst for electrochemical hydrogen generation. Nat. Commun. 2015, 6, 5982. [CrossRef] [PubMed]

66. Lukowski, M.A.; Daniel, A.S.; Meng, F.; Forticaux, A.; Li, L.; Jin, S. Enhanced hydrogen evolution catalysis from chemically exfoliated metallic $\mathrm{MoS}_{2}$ nanosheets. J. Am. Chem. Soc. 2013, 135, 10274-10277. [CrossRef] [PubMed]

67. Wang, H.; Lu, Z.; Xu, S.; Kong, D.; Cha, J.J.; Zheng, G.; Hsu, P.-C.; Yan, K.; Bradshaw, D.; Prinzb, F.B.; Cui, Y. Electrochemical tuning of vertically aligned $\mathrm{MoS}_{2}$ nanofilms and its application in improving hydrogen evolution reaction. Proc. Natl. Acad. Sci. USA 2013, 110, 19701-19706. [CrossRef] [PubMed]

68. Li, H.; Tsai, C.; Koh, A.L.; Cai, L.; Contryman, A.W.; Fragapane, A.H.; Zhao, J.; Han, H.S.; Manoharan, H.C.; Abild-Pedersen, F.; et al. Activating and optimizing $\mathrm{MoS}_{2}$ basal planes for hydrogen evolution through the formation of strained sulphur vacancies. Nat. Mater. 2016, 15, 48-50. [CrossRef] [PubMed]

69. Yang, L.; Fu, Q.; Wang, W.; Huang, J.; Huang, J.; Zhang, J.; Xiang, B. Large-area synthesis of monolayered $\mathrm{MoS}_{2}(1-\mathrm{x}) \mathrm{Se}_{2} \mathrm{xwith}$ a tunable band gap and its enhanced electrochemical catalytic activity. Nanoscale 2015, 7, 10490-10497. [CrossRef] [PubMed]

70. Ye, R.; del Angel-Vicente, P.; Liu, Y.; Arellano-Jimenez, M.J.; Peng, Z.; Wang, T.; Li, Y.; Yakobson, B.I.; Wei, S.-H.; Yacaman, M.J.; et al. High-performance hydrogen evolution from $\mathrm{MoS}_{2}(1-\mathrm{x}) \mathrm{Px}$ solid solution. Adv. Mater. 2016, 28, 1427-1432. [CrossRef] [PubMed]

71. Gong, Q.; Cheng, L.; Liu, C.; Zhang, M.; Feng, Q.; Ye, H.; Zeng, M.; Xie, L.; Liu, Z.; Li, Y. Ultrathin $\mathrm{MoS}_{2}(1-\mathrm{x}) \mathrm{Se}_{2} \mathrm{x}$ alloy nanoflakes for electrocatalytic hydrogen evolution reaction. ACS Catal. 2015, 5, 2213-2219. [CrossRef]

72. Yu, X.-Y.; Feng, Y.; Jeon, Y.; Guan, B.; Lou (David), X.W.; Paik, U. Formation of Ni-Co-MoS 2 Nanoboxes with Enhanced Electrocatalytic Activity for Hydrogen Evolution. Adv. Mater. 2016, 28, 9006-9011. [CrossRef] [PubMed]

73. Yang, L.; Wang, W.; Fu, Q.; Zhang, J.; Xiang, B. $\mathrm{MoS}_{2}(1-\mathrm{x}) \mathrm{Se}_{2} \mathrm{x}$ nanobelts for enhanced hydrogen evolution. Electrochim. Acta 2015, 185, 236-241. [CrossRef]

74. Fu, Q.; Yang, L.; Wang, W.; Han, A.; Huang, J.; Du, P.; Fan, Z.; Zhang, J.; Xiang, B. Synthesis and enhanced electrochemical catalytic performance of monolayer $\mathrm{WS}_{2}(1-\mathrm{x}) \mathrm{Se}_{2} \mathrm{x}$ with a tunable band gap. Adv. Mater. 2015, 27, 4732-4738. [CrossRef] [PubMed]

75. Kappera, R.; Voiry, D.; Yalcin, S.E.; Branch, B.; Gupta, G.; Mohite, A.D.; Chhowalla, M. Phase-engineered low-resistance contacts for ultrathin $\mathrm{MoS}_{2}$ transistors. Nat. Mater. 2014, 13, 1128-1134. [CrossRef] [PubMed]

76. Yu, Y.; Huang, S.-Y.; Li, Y.; Steinmann, S.N.; Yang, W.; Cao, L. Layer-dependent electrocatalysis of MoS $_{2}$ for hydrogen evolution. Nano Lett. 2014, 14, 553-558. [CrossRef] [PubMed] 
77. Ho, T.A.; Bae, C.; Lee, S.; Kim, M.; Montero-Moreno, J.M.; Park, J.H.; Shin, H. Edge-on MoS 2 thin films by atomic layer deposition for understanding the interplay between the active area and hydrogen evolution reaction. Chem. Mater. 2017. [CrossRef]

78. Velazquez, J.M.; John, J.; Esposito, D.V.; Pieterick, A.; Pala, R.; Sun, G.; Zhou, X.; Huang, Z.; Ardo, S.; Soriaga, M.P.; et al. A scanning probe investigation of the role of surface motifs in the behavior of $\mathrm{p}$-WSe photocathodes. Energy Environ. Sci. 2016, 9, 164-175. [CrossRef]

79. Qi, Y.; Xu, Q.; Wang, Y.; Yan, B.; Ren, Y.; Chen, Z. $\mathrm{CO}_{2}$-induced phase engineering: Protocol for enhanced photoelectrocatalytic performance of 2D MoS 2 nanosheets. ACS Nano 2016, 10, 2903-2909. [CrossRef] [PubMed]

80. Velický, M.; Bissett, M.A.; Woods, C.R.; Toth, P.S.; Georgiou, T.; Kinloch, I.A.; Novoselov, K.S.; Dryfe, R.A.W. Photoelectrochemistry of pristine mono- and few-layer $\mathrm{MoS}_{2}$. Nano Lett. 2016, 16, 2023-2032. [CrossRef] [PubMed]

81. Wong, J.; Jariwala, D.; Tagliabue, G.; Tat, K.; Davoyan, A.R.; Sherrott, M.C.; Atwater, H.A. High photovoltaic quantum efficiency in ultrathin van der Waals heterostructures. ACS Nano 2017, 11, 7230-7240. [CrossRef] [PubMed]

82. Jariwala, D.; Davoyan, A.R.; Tagliabue, G.; Sherrott, M.C.; Wong, J.; Atwater, H.A. Near-unity absorption in van der Waals semiconductors for ultrathin optoelectronics. Nano Lett. 2016, 16, 5482-5487. [CrossRef] [PubMed]

(C) 2017 by the authors. Licensee MDPI, Basel, Switzerland. This article is an open access article distributed under the terms and conditions of the Creative Commons Attribution (CC BY) license (http:/ / creativecommons.org/licenses/by/4.0/). 